\title{
The Spatial Structure of US Metropolitan Employment: New Insights from LODES Data
}

\author{
Robert Allen Manduca - rmanduca@g.harvard.edu
}

Urban researchers have long debated the extent to which urban employment is monocentric, polycentric, or diffuse. In this paper I use high-resolution data based on unemployment insurance records to show that employment in US metropolitan areas is not centralized but is spatially concentrated. Unlike residents, who form a continuous surface covering most parts of each MSA, jobs have a bimodal spatial distribution, with most blocks containing no jobs whatsoever and a small number having extremely high employment densities. Across the 100 largest MSAs about $75 \%$ of jobs are located on the $10 \%$ of built land in Census blocks with at least twice as many jobs as people. Further, most of these jobs are in clustered business districts of more than 5 contiguous employment blocks. These relative proportions are extremely consistent across MSAs, even though cities vary greatly in the physical density at which they are constructed. Motivated by these empirical regularities, I introduce an algorithm to identify contiguous business districts and classify them into four major types. Based solely on the relative densities of employment and population, this algorithm is both simpler to implement and more flexible than current approaches, requiring no metro-specific tuning parameters and no assumptions about urban form. As one output, it provides an inductive, data-driven method of identifying city centers for the purposes of urban economic analysis. 
Uncovering regularities in the spatial structure of cites has long been a passion of geographers, urban planners and regional scientists. In recent decades, a key portion of this effort has been directed at understanding the decentralization of employment. Following the suburbanization of the late $20^{\text {th }}$ century, it is now clear that the monocentric city model formalized by Alonso (1964) is no longer adequate to explain the geographic profiles of American cities. But there is debate about whether the most accurate alternative is a polycentric city featuring many subcenters, each a miniature version of the Central Business District (CBD), or a truly "edgeless" city (Lang, 2003) where employment is scattered almost at random throughout the metropolitan area.

In this paper I use block-level Census LODES data to study the spatial distribution of employment in the 100 largest US Metropolitan Statistical Areas (MSAs). I show that employment in these cities is not centralized, but it is still highly spatially concentrated. Jobs are found in all corners of most metros, but even in the exurbs they are tightly clustered into a relatively small number of Census blocks occupying only a minute fraction of the metros' built land area. These employment blocks form contiguous districts that define the employment geography of their cities.

The breakdown of land into residential, employment, and mixed use is remarkably consistent across cities. In at least 90 of the 100 largest metros, between 70 and $80 \%$ of jobs are found in what I term "employment blocks," which have twice as many jobs as residents. These employment blocks occupy just 5-10\% of the built land area. A further 10-20\% of jobs are found in mixed-use zones that occupy about $5 \%$ of built land. Only $10 \%$ of jobs are located in the remaining $80-90 \%$ of the land area. 
These empirical explorations show that the spatial distributions of jobs and residences are fundamentally different from one another. Population can be thought of as a surface, covering most of the metro area with areas of higher and lower density. But the spatial distribution of employment is much more bimodal: a few centers have large numbers of jobs in concentrations that dwarf even the densest residential neighborhoods, while most blocks have no employment whatsoever. Given this, the usefulness of modeling employment as a continuous surface is questionable. Rather, following Shearmur et al. (2007), I show that it can be productive to first identify the small number of employment blocks and then analyze their position and characteristics.

I introduce a subcenter identification algorithm based on the employment-population ratio, building on those of McDonald (1987), Forstall and Greene (1997), and Shearmur et al. (2007). This algorithm is both conceptually simpler and analytically more flexible than current approaches based exclusively on employment density. It is fully non-parametric and does not require local tuning parameters or any prior knowledge of a city's built form, not even the location of that city's Central Business District. In fact, it is able to identify the CBD with remarkable accuracy. Because it uses no metro area-specific parameters, it allows for the direct comparison of business districts across MSAs, something that is not possible with alternative approaches.

Such a comparison reveals that while metros are remarkably consistent in the relative amounts of land used for employment and residences, they differ a great deal in the form that each takes. I divide business districts into four categories based on their density, employment, and physical size. Traditional urban cores - the best approximation of the Central Business District in the monocentric city model-today contain about $16 \%$ of all metropolitan jobs, 
continuing to influence the employment landscapes of many MSAs. But large, continuously developed suburban districts are much more prominent, accounting for more than $40 \%$ of all jobs.

The development of the LODES dataset is a remarkable achievement, and it allows a much more detailed view into the spatial structure of US metros than has previously been possible. This paper represents a preliminary attempt to use this new data to better understand the spatial distribution of US metropolitan employment.

\section{Theorizing metropolitan spatial structure}

The spatial location of economic activity has been an important area of study for geographers and economists since at least Von Thunen (1966). He theorized an isolated city on a featureless plain, and described how in such a state land use would be determined by rent and transportation costs, resulting in a series of concentric zones of decreasing productivity and rents. Elaborations on Von Thunen's theory include the ecological model of the city developed by Burgess (1925) and Christaller's Central Place theory (1933), further developed by Losch (1954). For the most part, these early theoretical models described idealized cities with a single focal point or strict hierarchy of centers, an approach that was formalized in the monocentric city model of Alonso (1964).

Research since the 1960s has increasingly called into question the applicability of the monocentric model to US cities (Anas et al., 1998; Ladd and Wheaton, 1991). But scholars are divided as to what alternative is superior. The most common approach is to model today's cities as polycentric rather than monocentric (e.g. Fujita and Ogawa, 1982; Henderson and Mitra, 1996). Popularized in the book Edge City (Garreau, 2011), this approach holds that jobs and 
commerce are still concentrated in certain parts of the metro area, but in multiple employment centers rather than just one central business district.

Another view argues that polycentricity is just a stopping point on the way to a truly decentralized or scattered development (Gordon and Richardson, 1996). Rather than Edge Cities, this "scatteration" view argues that employment is increasingly concentrated in "Edgeless Cities" (Lang, 2003), amorphous office parks and employment districts scattered seemingly at random through the suburbs of most metropolitan areas.

The contrast between these two viewpoints highlights the distinction between employment centralization and employment concentration. Centralization measures the extent to which jobs are people are found near the center of a region or metro area, while concentration measures the extent to which they are found on a relatively small portion of its landmass (Galster et al., 2001; Lee, 2007). The subcenters outlook argues that jobs have been decentralized but remain concentrated, while the scatteration hypothesis argues that both decentralization and deconcentration have occurred.

Empirical investigations have found support for both polycentric and scattered employment. Various scholars have argued that a polycentric urban form predominates in cities from Phoenix (Leslie and HUallacháin, 2006) to Barcelona (Garcia-López and Muñiz, 2010) to Vienna (Helbich, 2012). Others have argued for the scatteration hypothesis (Lang et al., 2009), with some going so far as to claim that jobs have become almost as dispersed as residents (Wheaton, 2004). The extent to which employment is concentrated in one CBD, distributed across several subcenters, or widely dispersed may vary by city (Lee, 2007).

\section{Methods of identifying employment centers}


Accepting that some portion of employment is concentrated in certain districts, a robust literature has emerged around the creation of algorithms to identify employment centers. A few distinct approaches have been developed, each motivated by a slightly different theoretical idea of what an employment center is. The most straightforward and widely used approach is that of Giuliano and Small, who conceptualize subcenters as large centers of employment at high absolute densities (1991). In their study of Los Angeles, they identified subcenters as groups of contiguous transportation analysis zones with an employment density of at least 10 employees per acre and total employment of at least 10,000 jobs. This employment density threshold approach, with varying parameter values, has been adopted by other researchers in studies of Chicago (McMillen and Lester, 2003; McMillen and McDonald, 1998), San Francisco (Cervero and Wu, 1997), Cleveland (Bogart and Ferry, 1999), and Charlotte (Cho et al., 2008), among others (Fernández-Maldonado et al., 2014; Lee, 2007; Matsuo, 2011). In recent work, Ban, Arnott, and Macdonald expand the Giuliano and Small algorithm to allow it to better identify subcenters near the periphery of metropolitan areas (2017). The density threshold method has also been applied to other types of data, including cell phone activity (Louail et al., 2014).

A second method is motivated by the idea that subcenters are local maxima in an employment surface (McDonald, 1987). Several variations on this approach have been proposed (Craig and Ng, 2001; Redfearn, 2007). Perhaps the most prominent version is that of McMillen (McMillen, 2001a, 2004; McMillen and Smith, 2003), which first fits an employment density surface to the city, then identifies subcenters as areas with large positive residuals. Unlike the threshold-based approach, this local maxima approach does not require that subcenters meet an absolute density cutoff but asks instead whether they are relatively denser than neighboring areas. Density residual approaches have been widely used and applied to cities including 
Houston (Craig et al., 2016), Milwaukee (McMillen, 2001b), and Dublin (Vega and ReynoldsFeighan, 2008), as well as in multi-city comparisons (Lee, 2007). Though this approach has been most frequently used on employment data, it has been applied to other data sources as well, including nighttime light emissions (Chen et al., 2017).

A third approach also identifies subcenters as areas with higher than expected employment densities for their location, but uses techniques from exploratory spatial data analysis to identify these locations. The most common approach is to use Local Indicators of Spatial Association (Anselin, 1995) to identify statistically significant clusters of high density employment. This approach has been used in studies of Dijon (Baumont et al., 2004), Paris (Guillain et al., 2006), and Hermosillo (Rodríguez-Gámez and Dallerba, 2012), and in comparative studies of metros in Belgium (Riguelle et al., 2007) and the US (Arribas-Bel et al., 2015; Arribas-Bel and Sanz-Gracia, 2014). A similar application of exploratory spatial data analysis, but using the Getis-Ord statistic rather than the Local Moran's I, was used by Hajrasouliha and Hamidi (2017) in their typology of the spatial structures of US metros. That work is notable for being one of the first subcenter identification papers to make use of the highresolution LODES database, although it uses block groups as the unit of analysis rather than blocks as in the present study.

Finally and most directly related to this article, previous work using data with high spatial resolution has identified employment centers based on the relative proportions of jobs and residents. This was proposed as an alternative to employment density by MacDonald (1987) and developed more fully by Forstall and Greene (1997). Their study, focused on the Los Angeles metro area, noted that the employment to population ratio varied dramatically across the region, and that it did well at identifying zones with low absolute employment densities that nonetheless 
had large commuter inflows. Since then it has been used most notably in studies by Coffey, Shearmur, and colleagues of metropolitan areas in Canada (Coffey and Shearmur, 2001; Shearmur et al., 2007; Shearmur and Coffey, 2002). These studies have consistently shown that large portions of the studied metros have very few jobs, and that the majority of employment is found in a small number of employment zones with extremely high employment densities and few residents. Those empirical facts make the employment to population ratio an extremely straightforward and clean way to identify employment centers, one that can easily be applied to many metropolitan areas simultaneously. Despite these appealing features, this approach has not been widely used for subcenter identification in recent years.

In the remainder of this paper I reintroduce the employment to population ratio to the US context as a flexible and advantageous method of subcenter identification. After briefly describing the data used in this analysis, I begin by showing that urban employment in the United States today is decentralized but still is highly concentrated. I then motivate the use of the employment to population ratio by showing that the absolute densities of jobs and residences vary dramatically across the 100 MSAs, but the relative densities are remarkably constant. Further, metros are consistent in the proportions of their built land allocated to employment and residences, and most blocks contain exactly zero jobs. Given this, it is analytically straightforward to identify employment blocks as those few places with high employment densities, and to group contiguous employment blocks into business districts. I conclude by outlining a typology of four categories of business district, and noting that the largest district of one of those types - traditional urban cores - in each metro is a remarkably good proxy for the CBD. 


\section{Data}

I study the spatial location of employment using the Workplace Area Characteristics data files from the Census Longitudinal Employer-Household Dynamics Local Origin Destination Employment Statistics (LODES) for the year 2014 (U.S. Census Bureau, 2017). The LODES data is produced through a collaboration between the US Census Bureau and the labor market information offices of each state, and uses unemployment insurance records to provide information on the number of jobs in each Census block. Approximately $96 \%$ of wage and salary civilian jobs in the US are covered by unemployment insurance (U.S. Bureau of Labor Statistics, 1997). All such private sector jobs appear in the LODES data, as do most state and local government jobs and a portion of federal jobs. To avoid double-counting I further limit the sample to primary jobs, the job from which each person earned the most money in 2014. In total, the 2014 LODES data contains records of $125,697,883$ primary jobs, accounting for roughly 86\% of the Civilian Employment Level in the 2014 Current Population Survey (US Bureau of Labor Statistics, 2017).

Although the LODES data are extremely high quality on the whole, there are a few data quality concerns. Certain large, multi-sited employers do not disaggregate their employees by establishment, meaning that all employees are recorded as working at the headquarters. This is most notable in the cases of large public agencies such as school districts and public transportation agencies. I account for this by top-coding all blocks above an employment density of 500,000 jobs per square kilometer, roughly one and a half times the employment density of the block containing the Empire State Building. In addition, there are a small number of blocks that have zero land area but are coded as having jobs, which I exclude from the analysis. 
Data on the resident population of each Census block are from the 2010 Decennial Census, as compiled by the National Historical Geographic Information System (Manson et al., 2017). I focus this study on the 100 largest Metropolitan Statistical Areas (MSAs) as defined by the Office of Management and Budget in 2013 (Office of Management and Budget, 2013). These include all metro areas with more than 500,000 people and collectively contain almost 204 million residents and 86 million jobs, roughly $66 \%$ of the US population in 2010 Census and $69 \%$ of US primary jobs in the 2014 LODES data.

\section{Empirical Regularities in the spatial distribution of employment and population}

\section{Metropolitan employment is concentrated but not centralized}

The dispersal of employment beyond the city center has been well documented (Giuliano and Small, 1991; Glaeser and Kahn, 2001; Lang, 2003). This dispersal is present in the LODES data. A simple glance at a dot map of jobs shows that significant quantities of jobs are found in all corners of most metro areas, and by no means confined to one CBD. Figure 1 plots one dot

per job in the Boston (panel A) and Phoenix (panel B) MSAs. Even in Boston, famous as a dense and centralized metro, there are plenty of jobs outside of the $\mathrm{CBD}$, including many far out into the suburbs. From the map of Phoenix it is difficult to tell where downtown is. 
[Figure 1 about here]

But while the jobs shown in Figure 1 do not appear to be entirely centralized, they do seem to be clustered. In Boston, the Central Business District is obvious, connecting downtown and the Back Bay, as are clusters of jobs in the Kendall Square area of Cambridge, the Longwood Medical Area, and the Seaport District. Corridors of jobs are also visible following Massachusetts Avenue and the Massachusetts Turnpike from downtown out to the suburbs. In Phoenix, the downtown cluster is complimented by others in the Central Avenue Corridor, the Biltmore District, and in downtown Scottsdale.

The spatial distribution of residents is completely different. As shown in Figure 2, in both Boston and Phoenix residents are spread throughout the metro area, and they are much more evenly distributed than jobs are. Phoenix is noticeably less densely settled than Boston, and Boston shows something of a density gradient while Phoenix does not. But the differences in settlement patterns between the two cities are much smaller than the differences between the spatial patterns of residences and jobs within each metro.

[Figure 2 about here]

The spatial concentration of employment compared to population is present across the 100 largest MSAs. In all but 5 metro areas, the median employment density is higher than the median residential density, despite the fact that all MSAs have far more residents than jobs. This is the first result of the paper: while employment has indeed spread throughout most metropolitan areas, jobs remain highly spatially concentrated, far more so than residents. This 
finding contrasts with previous studies that have argued that jobs and residents are similarly dispersed (Glaeser and Kahn, 2001; Wheaton, 2004).

To quantify this phenomenon of concentration without centralization I adapt the methods used by Wheaton (2004). I first replicate his analysis of centralization, plotting the cumulative distribution of jobs and residents out from the CBD (as identified below). Figure 3a plots these distributions for the Boston MSA. In line with Wheaton's results, employment and population show similar patterns: jobs are more centralized than residents, but not much more.

Yet the similarity in this measure of centralization clearly fails to capture the substantial difference between the patterns shown in Figures 1a and 2a. It is clear that the spatial distributions of employment and population are very distinctive, and if that is not captured by the centralization measure used in Figure 3a a supplementary measure may be useful. As an alternative, I use a density-based concentration measure, where instead of ordering blocks by their distance from the CBD I order them by their density of residents and jobs (note that unlike the distance-based measure, this means a separate ordering for employment and population). This measure is similar to the Gini coefficient used by Small and Song (Small and Song, 1994), but more directly comparable to the Wheaton measure. Figure $3 \mathrm{~b}$ plots this density concentration curve for the Boston MSA. It shows a much clearer distinction between the spatial profiles of employment and population. Roughly $90 \%$ of Boston's jobs are on the densest $10 \%$ or so of built land, compared to only about $60 \%$ of its residents. That difference comes through very clearly in Figures 1a and 2a. 
[Figure 3 about here]

The patterns in Boston are characteristic of the 100 largest MSAs. Figure 4 plots distance and density concentration indexes for each MSA, computed by calculating the areas under the curves in Figure 3. In both cases the index for population is plotted on the x-axis and that for employment is plotted on the y-axis. In each case the dashed line denotes where the points would fall if employment and population were distributed similarly. From Figure 4a, it is clear that most cities are similar to Boston in that jobs are a bit, but not much, more centralized than residents. This pattern conforms to that noted by Wheaton (2004) and Glaeser and Kahn (2001). However, as Figure 4b shows, in every metro jobs are clustered much more tightly than residents are. In a clear break from the pattern in Figure 4a, Figure $4 \mathrm{~b}$ shows that employment is much more spatially concentrated than population. This suggests that it is incorrect to describe jobs and people as similarly distributed throughout metro areas.

[Figure 4 about here]

Distinguishing employment, residential, and mixed-use blocks

Most past investigations of intra-metropolitan employment distributions have conceptualized the spatial distribution of jobs as a continuous density surface. The local maxima of this surface are subcenters, sometimes identified explicitly as such (Craig and Ng, 2001; McMillen, 2001a; Redfearn, 2007), and other times more implicitly as collections of tracts with higher than average densities (Giuliano and Small, 1991). 
The maps in Figures 1 and 2 call this approach into question. While residents do appear to form something of a density surface, with areas of high and low density but a continuous presence across most of the metro, employment has a bimodal distribution. A few areas have extremely high employment densities, while most parts of the metro have hardly any jobs at all. In fact, in the median MSA $65 \%$ of built blocks representing $51 \%$ of the built land area have no jobs whatsoever. ${ }^{1}$ In contrast, no MSA lacks residents on more than $18 \%$ of its built land area, and the median MSA lacks residents on just $7 \%$ of its built land. Residents form an almost continuous presence across the built portion of all 100 metro areas; jobs do not.

These two facts - that jobs are tightly concentrated, and that the majority of blocks in every major city have no jobs at all - suggest that the most productive way to characterize the spatial distribution of employment may be not as a continuous surface with higher and lower densities in different places but as a set of discrete categories. As Shearmur et al. (2007) note in their study of Canadian metros, the majority of jobs in every city are found in a number of discrete "employment zones" scattered throughout a much larger residential area. At least at the block level, it makes sense to think of cities as composed of islands of employment in a sea of housing. Although a great deal of employment today is found in large-scale suburban office parks and shopping centers, even these occupy only a relatively small proportion of the built-up land area of most cities, and they tend to be clustered together.

To formalize this observation I follow Forstall and Greene (1997) and Shearmur et al. (2007) in using the employment to population ratio within each block to classify it based on its

\footnotetext{
${ }^{1}$ MSAs are defined using counties, and the size of counties varies greatly across the country. In some parts of the country counties containing cities also contain large areas of uninhabitable land, typically desert or swamp. For instance, $83 \%$ of the land in the Salt Lake City MSA is in blocks with no jobs and no residents, while less than 5\% of the land in Minneapolis or Cincinnati is similarly undeveloped. Because of this inconsistency I use the "built land area," defined as the land area of all blocks with at least one job or resident, rather than total land area when conducting area comparisons. See Appendix 1 for the percentage of land area in each MSA that is unbuilt.
} 
land use. I divide the built blocks of each MSA into three categories: employment, mixed-use, and residential. To be sure that only truly employment-centered areas are classified as such, I define employment blocks as those with at least twice as many jobs as residents. Residential blocks, conversely, have at least twice as many residents as jobs. The remaining mixed use blocks have comparable numbers of jobs and residents.

There is striking consistency across MSAs in the proportions of jobs and built land that fall into each of the three categories. Figure 5 plots the proportion of jobs and built land area contained in each category of blocks for each MSA. It shows three very clear clusters: employment blocks in the top left, residential blocks in the bottom right, and mixed-use blocks in the bottom left.

In each of the largest $100 \mathrm{MSAs}$, about $75 \%$ of jobs are located on employment blocks occupying about $10 \%$ of the built land. A further $10-20 \%$ of jobs are located in mixed blocks, which on average occupy about $5 \%$ of the land area. And only about $10 \%$ of jobs are found on the residential blocks that comprise the vast majority of each metro area. These proportions are remarkably consistent across cities as diverse as New York and Fresno, Seattle and Omaha, and Pittsburgh and Des Moines. As described in Appendix 2, this consistency in proportion despite wide variation in absolute density results from the high correlation between average residential and employment densities.

[Figure 5 about here]

\section{Identifying Business Districts}


Having shown that across the 100 largest MSAs most jobs are found in a relatively small number of employment blocks, there is still the question of whether these blocks are bunched together in major subcenters or spread out in "edgeless cities." To answer this question I calculate the extent to which employment blocks are clustered. After identifying employment blocks as described above, I group contiguous blocks together into business districts using the Geopandas and PySAL packages in Python (Rey and Anselin, 2007). Because Census blocks can be very small and are often separated by nothing more than a street, I allow for a buffer, counting blocks as contiguous if they come with 15 meters of each other at any one point. The choice of 15 meters appears to strike the best balance between grouping close-together blocks separated by small gaps such as streets while avoiding sprawling districts that cover huge portions of city and suburbs alike. ${ }^{2}$

Employment blocks are heavily clustered. More than $90 \%$ of all employment block jobs are found in business districts comprised of more than one contiguous block, and more than $78 \%$ of such jobs are found in districts of more than five. This overall pattern holds across all MSAs: between $59 \%$ and $89 \%$ of each metro's employment area jobs are found in clusters of at least

\footnotetext{
${ }^{2}$ The business district identification algorithm has two global parameters: the distance buffer below which nearby blocks will be counted as adjacent, and the ratio of jobs to people above which blocks are determined to be employment areas. There is no theoretical basis for favoring a particular value of either parameter. With each, a less restrictive value will increase the likelihood of grouping employment blocks into sprawling, internally varied districts. A more restrictive value, on the other hand, may result in splintering nearby blocks of similar character into multiple districts, which is also problematic. To empirically determine which set of parameters results in the best division of business districts I run the identification algorithm using all combinations of distance buffers of $0,15,20$, and 25 meters and ratio thresholds of 100\%, 150\%, 200\%, and 250\%. The extent to which heterogeneous blocks are grouped into the same business districts is measured using the coefficient of variation of both block area and employment density within each business district, averaged for each MSA weighting by the number of jobs in that district. To measure the extent to which nearby blocks are not being incorporated into the same business district I calculate the number of "near misses," additional jobs that would be added to each business district by expanding the buffer to 50 meters. I again take the average weighted by the number of jobs in each district. Changing the buffer size involves a direct tradeoff between internal diversity and near misses. Increasing the relative threshold decreases internal diversity without increasing the proportion of near misses, but at the cost of fewer overall jobs in employment areas. In the primary analysis I use cutoffs of $200 \%$ and 15 meters as they are intuitively appealing and near the middle on both outcome measures.
} 
five employment blocks. The probability of this concentration occurring by random chance is miniscule. To quantify this I randomly reshuffle employment across the blocks of each MSA 100 times, re-apply the clustering algorithm, and re-compute the fraction of employment in clustered business districts. In all cases, the observed fraction of jobs in clusters of more than five contiguous employment blocks is many times higher than that obtained via random shuffling. In the median MSA, the $95^{\text {th }}$ percentile of the random draws puts $6.2 \%$ of jobs in clusters of more than five blocks, while the median observed value is $76.7 \%$. No MSA has an observed value below $59.1 \%$, and the $95^{\text {th }}$ percentile of the random reshuffling is never greater than $16.1 \%$. Full results for all MSAs are presented in Appendix 3.

The algorithm I use to identify business districts as contiguous groups of employment blocks is an appealing alternative to subcenter identification algorithms based on employment density alone. Besides being conceptually simple and straightforward to implement, this algorithm can easily and simultaneously identify business districts in suburbs and central cities alike, a task previous algorithms have struggled with. This flexibility is demonstrated in Figure 6, which maps employment areas in the central New York City MSA. Identified business districts are outlined in black and shaded in grey over the satellite image. The algorithm clearly identifies Midtown and Downtown Manhattan, Downtown Brooklyn, Long Island City, and downtown Newark, while avoiding places like the Lower East Side and the Upper East and West Sides, which have employment densities higher than many suburban business districts but are predominantly residential neighborhoods.

[Figure 6 about here] 
Particularly striking is the fact that this algorithm is able to identify both Midtown Manhattan and the industrial areas in the Meadowlands of New Jersey as employment zones, while avoiding the dense residential area between them. Midtown has an overall employment density of roughly 160,000 jobs per square kilometer, while the Harmon Cove industrial area in Seacaucus (the large industrial area west of Midtown Manhattan, between the Hudson and Hackensack rivers), for instance, has a density of just 3,300 jobs $/ \mathrm{km}^{2}$, barely $2 \%$ as high. And yet both areas are clearly dominated by employment-each has more than 15 times as many jobs as residents within its boundaries - and both are major employment centers for the metropolitan region (Midtown is the single largest business district in the country, while Harmon Cove, with more than 30,000 jobs, is the $13^{\text {th }}$ largest business district in the New York MSA). An algorithm employing a fixed employment density threshold would be unable to identify both areas while avoiding the heavily developed but overwhelmingly residential northern portion of Manhattan. This inflexibility has been a major criticism of threshold-based algorithms in the past (Ban et al., 2017; Lee, 2007; McMillen, 2001a). While algorithms based on density surfaces could potentially identify both types of subcenter, the fact that these two areas are a mere five miles apart would put them at risk of being labeled as the same subcenter. Even if they were not grouped, it is unlikely that Harmon Cove would appear as a positive residual on a smoothed density surface, given how close it is to the center of the MSA.

A second appealing feature of this algorithm is that it returns areal units rather than single points. This allows metrics for each business district to be computed and other spatial data to be assigned to containing districts. The size and location of business districts can be mapped, allowing for quick visual assessment of the distribution of employment within a city. Figure 7 maps business districts in the Denver and Atlanta metro areas, with circles that are proportional 
in size to employment in each district. In Denver, downtown is immediately recognizable as a major concentration of jobs. But there are also large job centers in the suburbs, most notably in the Denver Tech Center in the southeastern portion of the metro area and in the industrial area northeast of downtown. Many smaller hubs are also visible throughout the metro area. Employment in Atlanta shows a similar pattern: there are clear centers in Downtown and Midtown Atlanta, as well as similarly sized business districts near the airport and in Perimeter Center.

[Figure 7 about here]

These distributions are typical. In most cities, there are 9 to 17 large business districts that contain at least $1 \%$ of total metro employment. Often, though not always, the historic CBD is among the largest of these. In the median MSA, the largest business district accounts for $10.5 \%$ of total employment, though that fraction ranges from $3 \%$ in Detroit to $30 \%$ in San Jose and Las Vegas. Summary statistics for all 100 MSAs are provided in Appendix 4. Maps of each MSA in the style of Figures 7 and 8 are available on the project website. As shown in Appendix 5, the size distribution of large business districts follows a rough power law, both at the national level and city by city.

A third advantage of the algorithm used here, which distinguishes it from previous subcenter identification algorithms applied to the United States, is that because the exact same algorithm is applied in each MSA, business districts in different cities are directly comparable to one another (Forstall and Greene, 1997; Shearmur and Coffey, 2002). This allows for cross-city comparisons in business district size, density, or composition. In terms of pure size, Midtown 
Manhattan, at just over 1.1 million jobs, is the largest business district in the country. It is

followed by the Chicago Loop (440,000 jobs), downtown Washington DC (359,000 jobs), Lower Manhattan (330,000 jobs), and downtown San Francisco (314,000 jobs), in that order. Appendix 6 provides summary statistics for the 20 largest business districts in the country.

\section{Business district categorization}

While cities are remarkably consistent in the percentage of jobs found in business districts, they vary a great deal in the form these business districts take. Here I identify and investigate four main types of business district based on district size and density. I first distinguish between large and small clusters of employment blocks. As shown above, most jobs are found in clusters of at least 5 employment blocks. These large clusters can be properly thought of as true "districts," distinct areas or neighborhoods that have some cohesive identity. In contrast, isolated clusters smaller than 5 blocks tend to be either the locations of a single dominant employer or small neighborhood centers unknown outside their immediate area.

I further divide clustered and isolated districts into two types each. Because density is so central to the experience of urban environments, I use it to differentiate among clustered business districts. I adopt a density threshold of 10,000 jobs per square kilometer as a demarcation between urban and suburban business districts. This is equivalent to approximately 150 jobs in a city block, a typical density for low-rise commercial areas in urban centers. If at least $75 \%$ of a business district's jobs are at this density, I label that district an "urban core.” When people imagine downtowns of skyscrapers, or even local, walkable retail shopping districts, this is what they have in mind. In total, urban cores make up just $0.1 \%$ of the built land area of the 100 
largest MSAs but contain $16 \%$ of the jobs. However, they vary in importance across MSAs, containing as many as $30 \%$ of all jobs in some MSAs while not even existing in others.

Second are large but sparse business districts, what I call "suburban strips.” With more than 5 blocks grouped together but employment densities below 10,000 jobs $/ \mathrm{km}^{2}$, these are the commercial and industrial developments that line the interstates leading out of many urban areas. They include office parks, warehouses, factories, and big box stores that typically have their own parking lots but form continuous stretches of economic activity that can go on for miles.

Suburban strips are by far the dominant employment form of in the US, containing a full $44 \%$ of all metropolitan jobs on about 3\% of the built land area. Notably, even though they cover 27 times as much land area as urban cores, they still occupy only a tiny portion of the built area of most cities. While urban cores vary greatly in importance across the 100 largest MSAs, containing shaping the employment landscape of some cities will not even existing in others, suburban strips are an important presence in all 100 metros, always containing at least a quarter of all employment.

Because isolated districts are composed of so few blocks, density is less useful in capturing their character than sheer size. Some of these isolated districts are truly massive, even though they are concentrated on a few blocks. For example, the headquarters of $3 \mathrm{M}$ in the suburbs of St. Paul, Minnesota forms its own one-block business district. But it still is home to more than 17,000 jobs, and is by itself the 11th largest business district in the Minneapolis MSA. I label isolated business districts with more than 500 jobs "independent" districts. Though they are not always well integrated into the urban fabric, independent districts still heavily influence the employment landscape of their respective cities. In many cases they contain hospitals or universities that employ huge numbers of people and offer the possibility of serving as anchor 
institutions for surrounding neighborhoods. In total, these independent districts account for $10 \%$ of metropolitan employment on $0.5 \%$ of the built land area.

Finally, many isolated business districts are simply a few blocks by themselves with only a small number of jobs. These "dispersed" districts of fewer than 5 blocks and fewer than 500 jobs account for the numerical majority of business districts, and about half of the land area contained in employment blocks (3\% of the all built land). However, they contain only about $7 \%$ of jobs.

Figure 8 maps business districts by category in the New York MSA. The red shaded business districts are the traditional urban cores: places like Midtown Manhattan, Lower Manhattan, downtown Brooklyn, and downtown Newark that were the original centers of economic activity in the region. Purple shaded areas are suburban strips, in this case largely encompassing the industrial portions of New Jersey and New York City. Light green areas are independent centers, including La Guardia Airport and Columbia University. And turquoise areas are scattered employment districts with limited employment.

[Figure 8 about here]

In sum, all jobs in the 100 largest MSAs fall into one of six types of area. About $10 \%$ of jobs are in residential areas, where they are outnumbered more than two to one by residents. Another $13 \%$ are in mixed areas with similar numbers of jobs and residents. The employment areas that contain the remaining $76 \%$ of jobs can be divided into four types of business district with very different characters: traditional urban cores (16\% of employment), suburban strips 
$(44 \%)$, independent centers $(10 \%)$ and dispersed blocks $(7 \%)$. Table 1 gives the exact breakdown of jobs, residents, and built land for the 100 MSAs taken together.

[Table 1 about here]

Although the national numbers are informative, there is a huge amount of variation among MSAs in how jobs are distributed across the various types of employment district. Three of the 100 largest MSAs have no business districts that qualify as a traditional urban core, for instance, while New York has 104, which collectively account for over quarter of its employment.

Figure 9 shows the breakdown of MSAs into the various categories. Apart from New York City, Honolulu, Houston, New Orleans, San Francisco, Washington DC, and Jackson, Mississippi have at least $25 \%$ of their overall employment in traditional urban cores. 24 further cities, including Boston, Atlanta, Nashville, Seattle, and Chicago, have over $15 \%$ of their employment in urban cores. These cities have important downtowns, and many are considered exemplars of urbanism, but at the metro level suburban employment clearly dominates. On the other end of the spectrum, Fresno, CA, Ogden, UT, and Palm Bay, FL have no urban cores that meet the requisite density thresholds, while 16 other cities have fewer than $5 \%$ of their jobs in traditional urban cores.

[Figure 9 about here]

Identification of Central Business Districts 
The presence of urban core business districts in almost every major city provides a way to identify city centers for the purposes of urban geographic analysis. Many theoretical and empirical attempts to understand metropolitan structure have been undertaken in reference to a Central Business District or other central point. But systematically defining and identifying such places has proven difficult. In many cases scholars have had to resort to ad hoc or manually created CBD definitions, which are both nonscalable and difficult to characterize. A large number of papers rely on a table produced from the 1982 Economic Census, which identified the tract or tracts containing the Central Business District of metro areas of 50,000 or more people (e.g. Baum-Snow, 2007; Glaeser and Kahn, 2001; Ottensmann, 2016). However, these estimates are more than 30 years old, they exist only for cities that met the size threshold in 1982 and also chose to participate, and they were constructed in part via a survey of local leaders, a method that is difficult to replicate (Glaeser and Kahn, 2004; U.S. Bureau of the Census, 1983). An alternative approach has been to use the location of City Hall (Ottensmann, 2016) or a prominent commercial building (Haughwout et al., 2008). Recently there have been promising attempts to identify city centers using Volunteered Geographic Information (Hollenstein and Purves, 2010; Sun et al., 2016; Yu et al., 2015).

The urban core business districts identified here provide a systematic and transparent method of identifying the CBD or city center. The largest urban core business district is labeled the Central Business District, and its employment-weighted centroid is the point from which distances are measured. If a metro has no urban core district with at least $1 \%$ of overall employment, the single largest business district of any type is used instead. This constraint applies in seven cities. This approach provides a single, rigorous way of determining the CBD of any metro area that is easy to update and based solely on current employment data. 
The CBDs identified using this approach closely match intuitive and inspection-based conceptions of the center of town, but they emerge entirely and consistently from the employment data. As a proxy for the intuitive centers of each metro area, I compare the CBDs identified here to the locations returned by the Google Maps API as the center of the largest principal city of each MSA. In 81 of the 100 MSAs I study the CBD identified using this algorithm and that identified by Google are less than two miles apart, and in at least eight of the discrepancies the location selected by the algorithm is arguably closer to the true city center than that identified by Google. ${ }^{3}$ A full list of the CBD coordinates for each of the 100 largest MSAs as identified using this algorithm and from Google Maps is presented in Appendix 7.

\section{Discussion}

In this paper I have offered several observations on the spatial structure of metropolitan employment in the United States. First, I have shown definitively that US metropolitan jobs are neither centralized nor dispersed. Rather, they are found in local concentrations that can appear throughout metropolitan areas. Across the 100 largest MSAs, about $75 \%$ of jobs are contained in the $15 \%$ of built land area with more than twice as many jobs as people. That is a sharp contrast to the spatial patterns of residents, who are spread much more evenly across a much larger portion of the metro area. This pattern of concentration without centralization confirms the inadequacy of the monocentric city model for today's cities, and also highlights the limitations of models that only consider a location's distance from downtown.

\footnotetext{
${ }^{3}$ For instance, the algorithm used here identifies Midtown Manhattan as the CBD of the New York MSA, while Google Maps returns downtown Manhattan, consistent with the historic development of the city. In polycentric MSAs such as Virginia Beach, VA, Bridgeport, CT, and several metro areas in Florida, the largest business districts are in cities that are not the most populous of the MSA (Norfolk and Stamford in the cases of Virginia Beach and Bridgeport).
} 
Because the majority of built urban land contains no jobs at all, and because the proportions of land devoted to employment and residences are remarkably consistent across the 100 largest MSAs, I have argued that modeling employment as a continuous density surface can be misleading. Instead, I have reintroduced to the US context the employment-population ratio as a method of classifying blocks according to their land use. Blocks with more than twice as many jobs as residents are classified as employment blocks, while those with twice as many residents as jobs are residential. Mixed-use blocks contain comparable numbers of residents and jobs. Contiguous employment blocks are grouped together into business districts, which I further categorize based on their size and density.

This approach both more consistent and more flexible than most previous methods of subcenter identification. Because it identifies districts based on land use rather employment density it is able to perform well in both urban and suburban areas simultaneously. Further, since the exact same algorithm is used in all metros without any local fitting or tuning parameters, the identified business districts are comparable across cities, allowing for clear statements about the relative size of business districts in places as diverse as New York and Boise. Finally, this approach is more analytically straightforward and easier to implement than density surface-based procedures.

There are limitations to the business district identification algorithm used here, however. Most notably, it still relies on two global parameters, the ratio of employment to jobs above which blocks are deemed employment blocks, and the buffer distance below which two blocks are considered contiguous. There is no theoretical rationale for picking any one specific value of either parameter, and while the results are reasonably robust, changes to the buffer distance in particular can result in the grouping or fragmentation of very large business districts. Perhaps 
more concerning, in some cases the buffer that appears to make the most sense for downtown areas may result in the fragmentation of suburban business districts, especially those built on opposite sides of interstate highways. These cases are not difficult to diagnose and correct visually, so should not inhibit the use of these methods among practitioners in individual metro areas, but they may cause difficulty in comparative studies.

It is also worth noting that the concept of a business district based on land use that I use here is slightly distinct from that of an employment subcenter defined by job density. However, both approaches capture similar numbers of jobs, trading of jobs in high-density residential areas for those in low-density employment areas. It is thus debatable which best captures the spatial structure of employment, and I choose land use for its greater analytical simplicity and comparability across metro areas.

The employment geography of the United States combines incredible local intricacy with broad consistency at the metropolitan level. New high resolution administrative data are able to document these patterns with a level of detail previously unavailable. As shown in this paper, these data offer new perspective on longstanding debates and suggest updates to how metropolitan spatial structure is theorized and modeled. 


\section{Works Cited}

Alonso W (1964) Location and land use. Toward a general theory of land rent. Location and land use. Toward a general theory of land rent. Available at: https://www.cabdirect.org/cabdirect/abstract/19641802976 (accessed 23 September 2017).

Anas A, Arnott R and Small KA (1998) Urban spatial structure. Journal of economic literature 36(3): 1426-1464.

Anselin L (1995) Local Indicators of Spatial Association-LISA. Geographical Analysis 27(2): 93-115. DOI: 10.1111/j.1538-4632.1995.tb00338.x.

Arribas-Bel D and Sanz-Gracia F (2014) The validity of the monocentric city model in a polycentric age: US metropolitan areas in 1990, 2000 and 2010. Urban Geography 35(7): 980-997. DOI: 10.1080/02723638.2014.940693.

Arribas-Bel D, Ramos A and Sanz-Gracia F (2015) The size distribution of employment centers within the US Metropolitan Areas. Environment and Planning B: Planning and Design 42(1): 23 - 39. DOI: 10.1068/b39038.

Ban J, Arnott R and Macdonald JL (2017) Identifying Employment Subcenters: The Method of Exponentially Declining Cutoffs. Land 6(1): 17. DOI: 10.3390/land6010017.

Baumont C, Ertur C and Gallo J (2004) Spatial analysis of employment and population density: the case of the agglomeration of Dijon 1999. Geographical analysis 36(2): 146-176.

Baum-Snow N (2007) Did Highways Cause Suburbanization? The Quarterly Journal of Economics 122(2): 775-805.

Bogart WT and Ferry WC (1999) Employment Centres in Greater Cleveland: Evidence of Evolution in a Formerly Monocentric City. Urban Studies 36(12): 2099-2110. DOI: $10.1080 / 0042098992566$.

Burgess EW (1925) The Growth of the City: An Introduction to a Research Project. In: The City. Chicago: University of Chicago Press.

Cervero R and Wu K-L (1997) Polycentrism, Commuting, and Residential Location in the San Francisco Bay Area. Environment and Planning A 29(5): 865-886. DOI: 10.1068/a290865.

Chen Z, Yu B, Song W, et al. (2017) A New Approach for Detecting Urban Centers and Their Spatial Structure With Nighttime Light Remote Sensing. IEEE Transactions on Geoscience and Remote Sensing PP(99): 1-15. DOI: 10.1109/TGRS.2017.2725917.

Cho EJ, Rodriguez DA and Song Y (2008) The Role of Employment Subcenters in Residential Location Decisions. DOI: 10.5198/jtlu.v1i2.65. 
Christaller W (1933) Central places in southern Germany. Englewood Cliffs, NJ: Prentice-Hall.

Coffey WJ and Shearmur RG (2001) The identification of employment centres in Canadian metropolitan areas: the example of Montreal, 1996. Canadian Geographer / Le Géographe canadien 45(3): 371-386. DOI: 10.1111/j.1541-0064.2001.tb01188.x.

Craig SG and Ng PT (2001) Using quantile smoothing splines to identify employment subcenters in a multicentric urban area. Journal of Urban Economics 49(1): 100-120.

Craig SG, Kohlhase JE and Perdue AW (2016) Empirical Polycentricity: The Complex Relationship Between Employment Centers. Journal of Regional Science 56(1): 25-52.

Fernández-Maldonado AM, Romein A, Verkoren O, et al. (2014) Polycentric Structures in Latin American Metropolitan Areas: Identifying Employment Sub-centres. Regional Studies 48(12): 1954-1971. DOI: 10.1080/00343404.2013.786827.

Forstall RL and Greene RP (1997) Defining Job Concentrations: The Los Angeles Case. Urban Geography 18(8): 705-739. DOI: 10.2747/0272-3638.18.8.705.

Fujita M and Ogawa H (1982) Multiple equilibria and structural transition of non-monocentric urban configurations. Regional science and urban economics 12(2): 161-196.

Galster G, Hanson R, Ratcliffe MR, et al. (2001) Wrestling sprawl to the ground: defining and measuring an elusive concept. Housing policy debate 12(4): 681-717.

Garcia-López M-À and Muñiz I (2010) Employment decentralisation: Polycentricity or scatteration? The case of Barcelona. Urban Studies. Available at: http://usj.sagepub.com.ezpprod1 .hul.harvard.edu/content/early/2010/06/22/0042098009360229.abstract (accessed 29 August 2016).

Garreau J (2011) Edge city: Life on the new frontier. Anchor. Available at: https://books-googlecom.ezpprod1 .hul.harvard.edu/books?hl=en\&lr=\&id=_h4eF9H9UtQC\&oi=fnd\&pg=PR19\&dq=e dge+city\&ots=COVJsfNhK4\&sig=wBjoEv-YUeEGfYVGcZI8PTwOiTk (accessed 31 August 2016).

Giuliano G and Small KA (1991) Subcenters in the Los Angeles region. Regional Science and Urban Economics 21(2): 163-182. DOI: 10.1016/0166-0462(91)90032-I.

Glaeser EL and Kahn ME (2001) Decentralized employment and the transformation of the American city. National Bureau of Economic Research. Available at: http://www.nber.org.ezp-prod1.hul.harvard.edu/papers/w8117 (accessed 7 November 2014).

Glaeser EL and Kahn ME (2004) Sprawl and urban growth. Handbook of regional and urban economics 4: 2481-2527. 
Gordon P and Richardson HW (1996) Beyond polycentricity: the dispersed metropolis, Los Angeles, 1970-1990. Journal of the American Planning Association 62(3): 289-295.

Guillain R, Le Gallo J and Boiteux-Orain C (2006) Changes in Spatial and Sectoral Patterns of Employment in Ile-de-France, 1978-97. Urban Studies 43(11): 2075-2098. DOI: 10.1080/00420980600945203.

Hajrasouliha AH and Hamidi S (2017) The typology of the American metropolis: monocentricity, polycentricity, or generalized dispersion? Urban Geography 38(3): 420444. DOI: $10.1080 / 02723638.2016 .1165386$.

Haughwout A, Orr J and Bedoll D (2008) The Price of Land in the New York Metropolitan Area. ID 1138790, Current Issues in Economics and Finance, May. New York, NY, US: New York Fed. Available at: https://papers.ssrn.com/abstract=1138790 (accessed 26 September 2017).

Helbich M (2012) Beyond postsuburbia? Multifunctional service agglomeration in Vienna's urban fringe. Tijdschrift voor economische en sociale geografie 103(1): 39-52.

Henderson V and Mitra A (1996) The new urban landscape: Developers and edge cities. Regional Science and Urban Economics 26(6): 613-643. DOI: 10.1016/S01660462(96)02136-9.

Hollenstein L and Purves R (2010) Exploring place through user-generated content: Using Flickr tags to describe city cores. Journal of Spatial Information Science 2010(1): 21-48.

Ladd HF and Wheaton W (1991) Causes and consequences of the changing urban form: Introduction. Regional Science and Urban Economics 21(2): 157-162. DOI: 10.1016/0166-0462(91)90031-H.

Lang RE (2003) Edgeless cities: Exploring the elusive metropolis. Brookings Institution Press. Available at: https://books-google-com.ezpprod1.hul.harvard.edu/books?hl=en\&lr=\&id=9JKVSLGKPMC\&oi=fnd\&pg=PR9\&dq=lang+edgeless+city\&ots=bkoacWQPMX\&sig= OR9kgpc8bGPsbccGF7aWxaZTbs4 (accessed 29 August 2016).

Lang RE, Sanchez TW and Oner AC (2009) Beyond edge city: office geography in the new metropolis. Urban Geography 30(7): 726-755.

Lee B (2007) "edge" or "edgeless" Cities? Urban Spatial Structure in U.s. Metropolitan Areas, 1980 to 2000*. Journal of Regional Science 47(3): 479-515. DOI: 10.1111/j.14679787.2007.00517.x.

Leslie TF and HUallacháin BÓ (2006) Polycentric phoenix. Economic Geography 82(2): 167192.

Losch A (1954) Economics of location. 
Louail T, Lenormand M, Ros OGC, et al. (2014) From mobile phone data to the spatial structure of cities. Scientific Reports 4. DOI: 10.1038/srep05276.

Manson S, Schroeder J, Van Riper D, et al. (2017) IPUMS National Historical Geographic Information System: Version 12.0. Minneapolis: University of Minnesota. Available at: http://doi.org/10.18128/D050.V12.0.

Matsuo M (2011) US Metropolitan Spatial Structure and Labour Accessibility. Urban Studies 48(11): 2283-2302. DOI: 10.1177/0042098010380954.

McDonald JF (1987) The identification of urban employment subcenters. Journal of Urban Economics 21(2): 242-258. DOI: 10.1016/0094-1190(87)90017-9.

McMillen DP (2001a) Nonparametric Employment Subcenter Identification. Journal of Urban Economics 50(3): 448-473. DOI: 10.1006/juec.2001.2228.

McMillen DP (2001b) Polycentric urban structure: The case of Milwaukee. Chicago: Federal Reserve Bank of Chicago.

McMillen DP (2004) Employment densities, spatial autocorrelation, and subcenters in large metropolitan areas. Journal of regional science 44(2): 225-244.

McMillen DP and Lester TW (2003) Evolving subcenters: employment and population densities in Chicago, 1970-2020. Journal of Housing Economics 12(1): 60-81.

McMillen DP and McDonald JF (1998) Suburban Subcenters and Employment Density in Metropolitan Chicago. Journal of Urban Economics 43(2): 157-180. DOI: 10.1006/juec.1997.2038.

McMillen DP and Smith SC (2003) The number of subcenters in large urban areas. Journal of Urban Economics 53(3): 321-338. DOI: 10.1016/S0094-1190(03)00026-3.

Office of Management and Budget (2013) Revised Delineations of Metropolitan Statistical Areas, Micropolitan Statistical Areas, and Combined Statistical Areas, and Guidance on Uses of the Delineations of These Areas. 13. Available at:

http://www.whitehouse.gov/sites/default/files/omb/bulletins/2013/b-13-01.pdf.

Ottensmann JR (2016) The Negative Exponential Decline of Density in Large Urban Areas in the U.S., 1950-2010. ID 2888119, SSRN Scholarly Paper, 1 October. Rochester, NY: Social Science Research Network. Available at: https://papers.ssrn.com/abstract=2888119 (accessed 23 September 2017).

Redfearn CL (2007) The topography of metropolitan employment: Identifying centers of employment in a polycentric urban area. Journal of Urban Economics 61(3): 519-541.

Rey SJ and Anselin L (2007) PySAL: A Python Library of Spatial Analytical Methods. The Review of Regional Studies 37(1): 5-27. 
Riguelle F, Thomas I and Verhetsel A (2007) Measuring urban polycentrism: a European case study and its implications. Journal of Economic Geography. Available at: http://joeg.oxfordjournals.org.ezpprod1.hul.harvard.edu/content/early/2007/01/09/jeg.lb1025.short (accessed 9 May 2016).

Rodríguez-Gámez L and Dallerba S (2012) Spatial Distribution of Employment in Hermosillo, 1999-2004. Urban Studies 49(16): 3663-3678. DOI: 10.1177/0042098012448552.

Shearmur R and Coffey WJ (2002) A tale of four cities: intrametropolitan employment distribution in Toronto, Montreal, Vancouver, and Ottawa-Hull, 1981-1996. Environment and Planning A 34(4): 575-598.

Shearmur R, Coffey W, Dube C, et al. (2007) Intrametropolitan employment structure: Polycentricity, scatteration, dispersal and chaos in Toronto, Montreal and Vancouver, 1996-2001. Urban Studies 44(9): 1713-1738.

Small KA and Song S (1994) Population and Employment Densities: Structure and Change. Journal of Urban Economics 36(3): 292-313. DOI: 10.1006/juec.1994.1037.

Sun Y, Fan H, Li M, et al. (2016) Identifying the city center using human travel flows generated from location-based social networking data. Environment and Planning B: Planning and Design 43(3): 480-498. DOI: 10.1177/0265813515617642.

U.S. Bureau of Labor Statistics (1997) Ch. 5, Employment and Wages Covered by Unemployment Insurance. In: BLS Handbook of Methods. Washington, D.C.: US Department of Labor, pp. 42-47. Available at: http://www.bls.gov/opub/hom/homch5_b.htm (accessed 16 February 2015).

US Bureau of Labor Statistics (2017) Civilian Employment Level [CE16OV]. 23 September. FRED, Federal Reserve Bank of St. Louis. Available at: https://fred.stlouisfed.org/series/CE16OV.

U.S. Bureau of the Census (1983) 1982 economic censuses: geographic reference manual. Reference series / U.S. Dept. of Commerce, Bureau of the Census ;EC82-R-1. Washington, D.C.: U.S. Dept. of Commerce, Bureau of the Census. Available at: https//catalog.hathitrust.org/Record/009795697 (accessed 23 September 2017).

U.S. Census Bureau (2017) LEHD Origin-Destination Employment Statistics Data (2002-2015). Wasington DC: U.S. Census Bureau, Longitudinal Employer-Household Dynamics Program. Available at: https://lehd.ces.census.gov/data/\#lodes.

Vega A and Reynolds-Feighan A (2008) Employment Sub-centres and Travel-to-Work Mode Choice in the Dublin Region. Urban Studies 45(9): 1747-1768. DOI: $10.1177 / 0042098008093377$.

Von Thünen JH (1966) Isolated state. Pergamon Press. 
Wheaton WC (2004) Commuting, congestion, and employment dispersal in cities with $<\mathrm{i}>$ mixed </i> land use. Journal of Urban Economics 55(3): 417-438.

Yu W, Ai T and Shao S (2015) The analysis and delimitation of Central Business District using network kernel density estimation. Journal of Transport Geography 45: 32-47. DOI: 10.1016/j.jtrangeo.2015.04.008. 
Figures and Tables

A. Boston

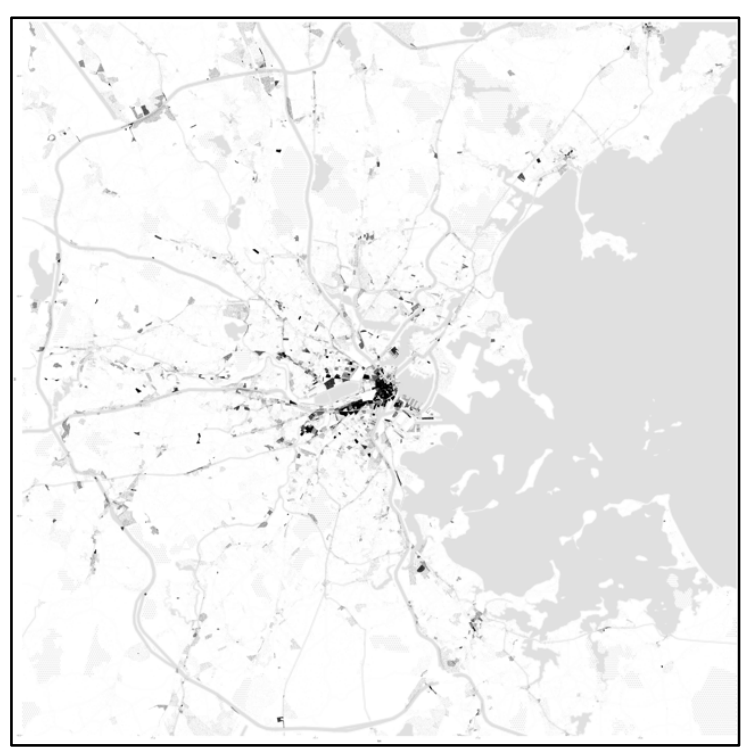

B. Phoenix

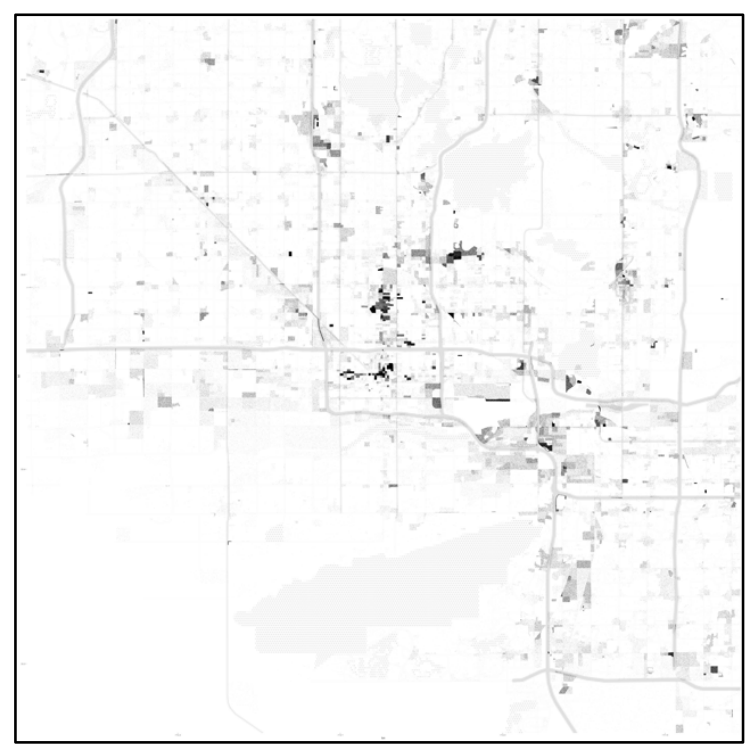

Figure 1. Dot density maps of jobs in Boston (A) and Phoenix (B). Background imagery by Stamen Design under CC BY 3.0; map data by Open Street Map under ODbL 
A. Boston

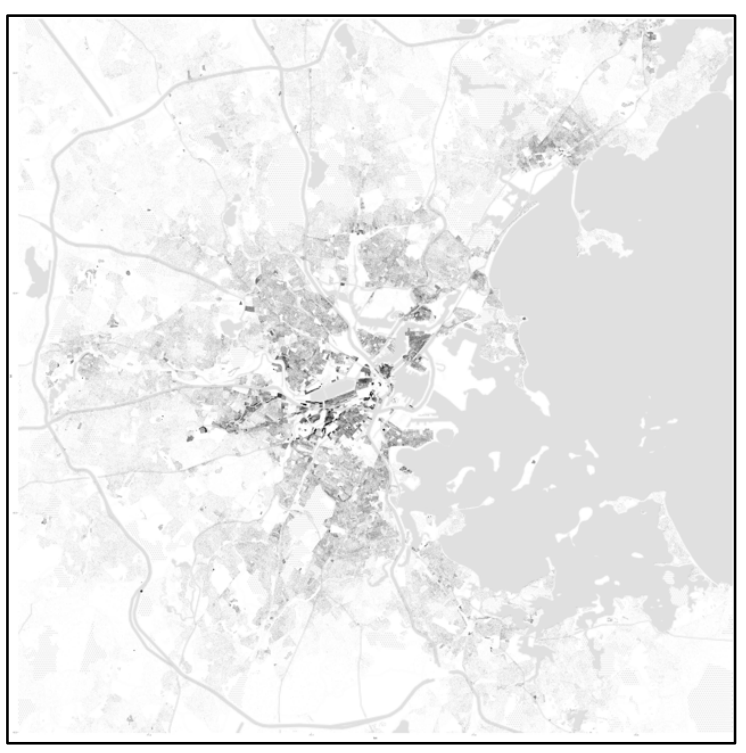

B. Phoenix

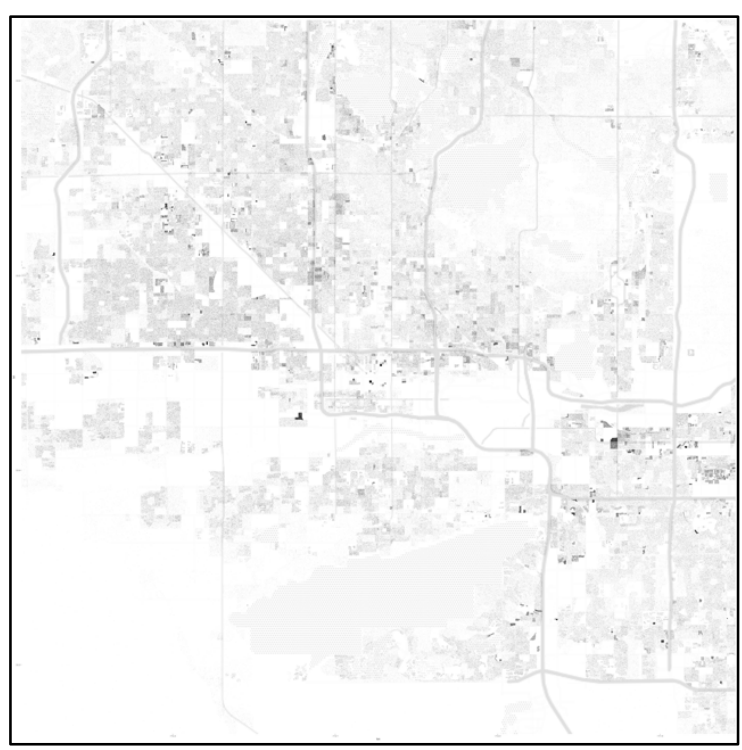

Figure 2. Dot density maps of residents in Boston (A) and Phoenix (B). Background imagery from Stamen Design by under CC BY 3.0; map data from Open Street Map under ODbL 

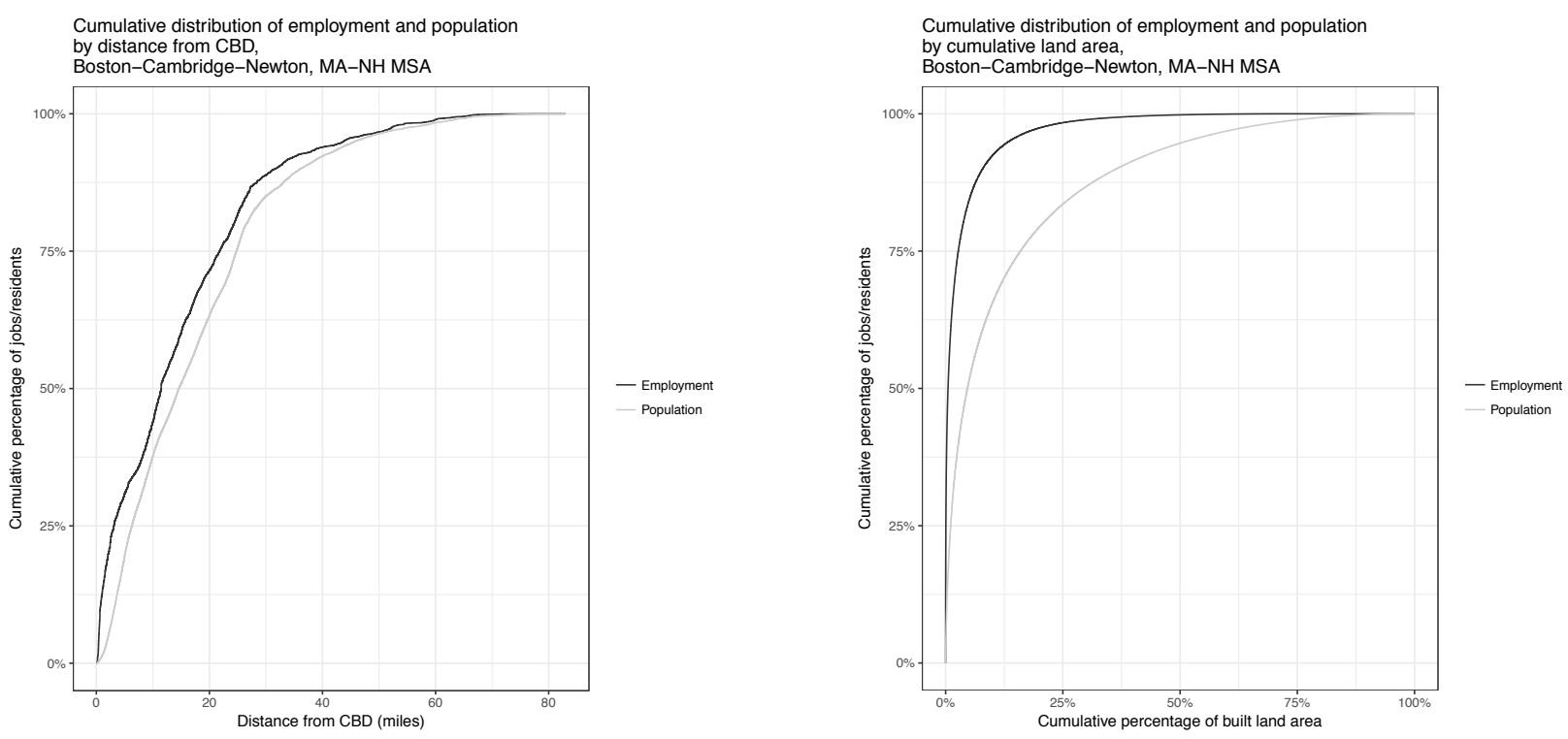

Figure 3. Cumulative distribution of jobs and residents by distance from CBD (A) and density (B), Boston MSA 

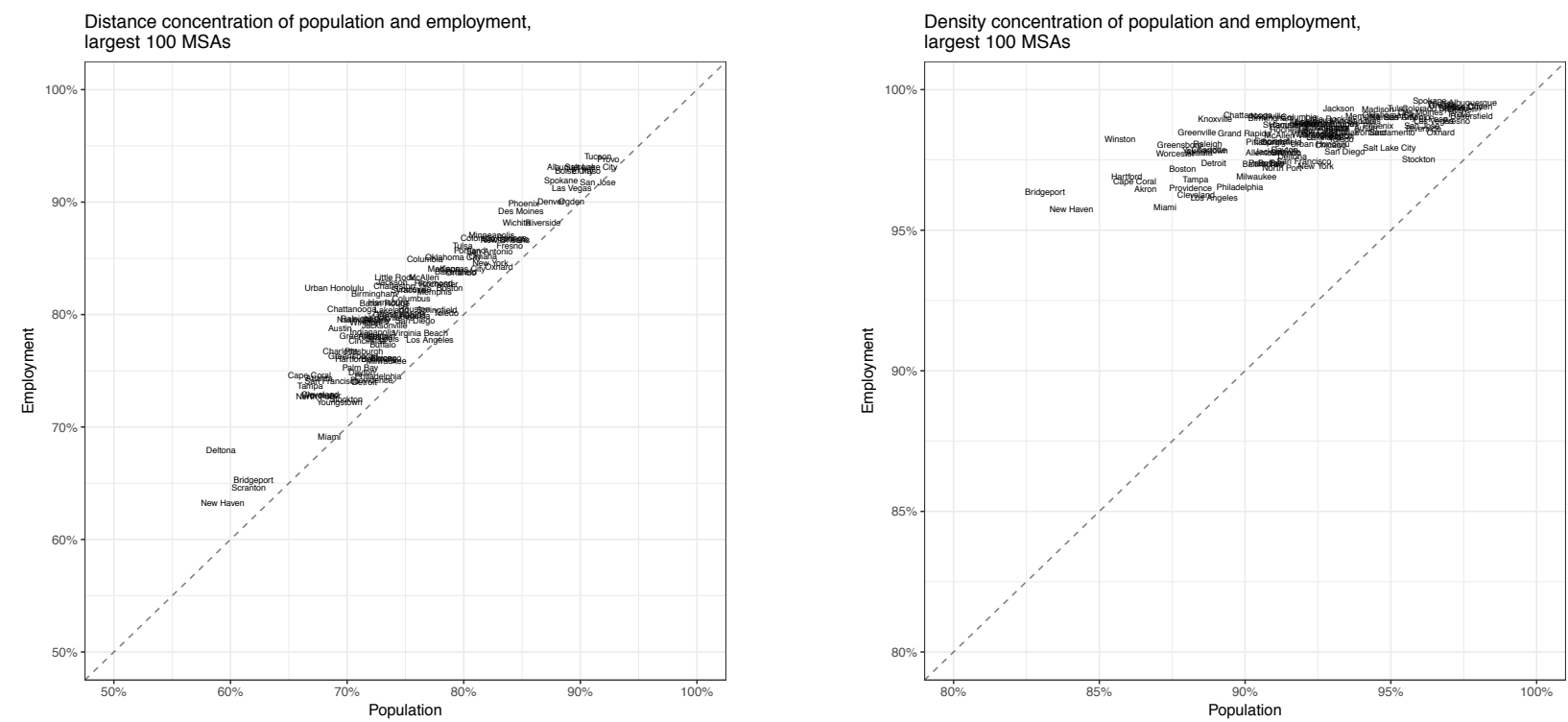

Figure 4. Distance (A) and density (B) concentration indices for population and employment, 100 largest MSAs. 


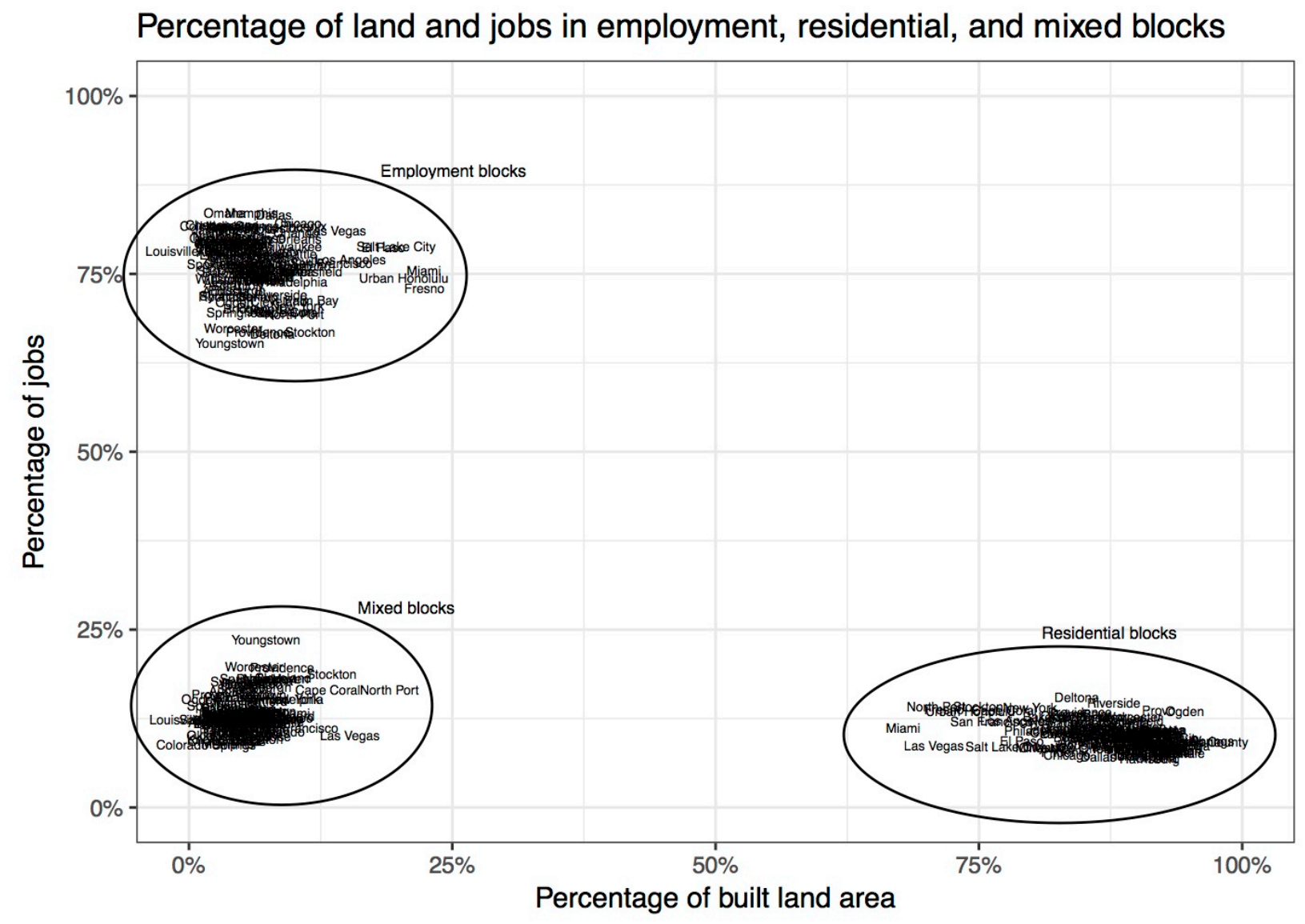

Figure 5. Percentage of land and jobs in employment, residential, and mixed blocks, 100 largest MSAs 


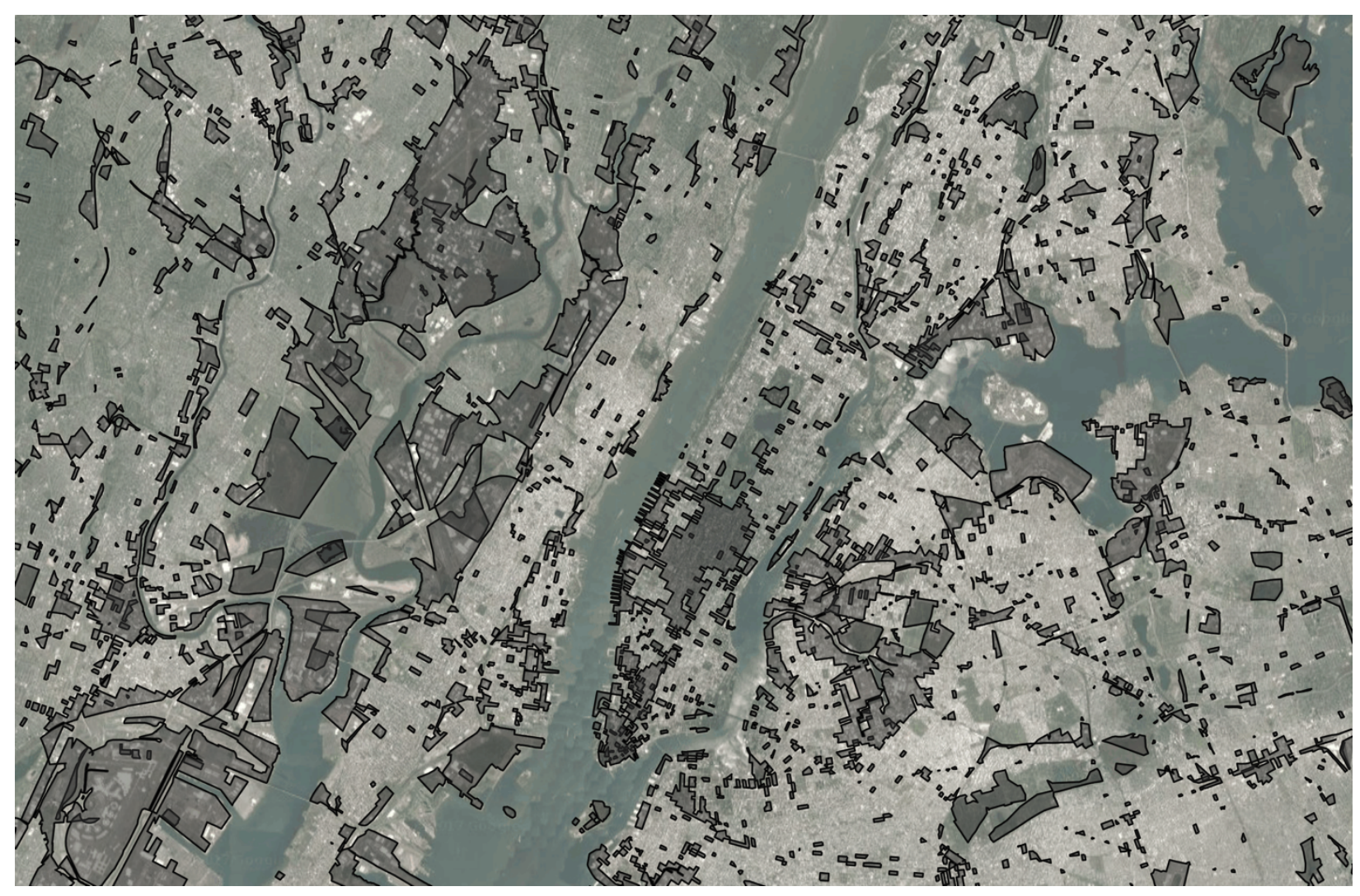

Figure 6. Business districts in the central New York City MSA. Background map CGoogle 2017 

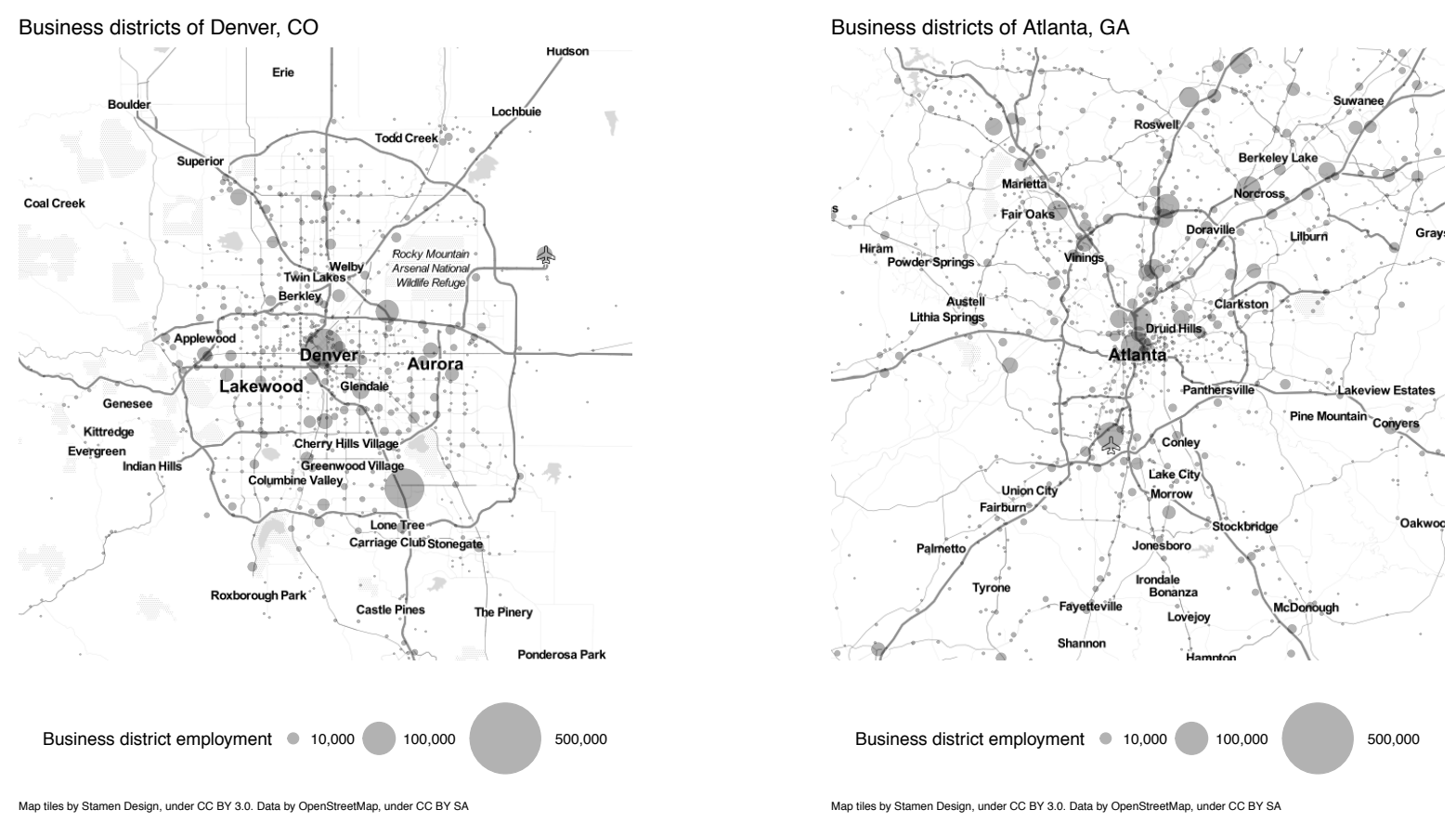

Map tiles by Stamen Design, under CC BY 3.0. Data by OpenStreetMap, under CC BY SA

Figure 7. Business districts of the Denver, CO and Atlanta, GA metropolitan areas 


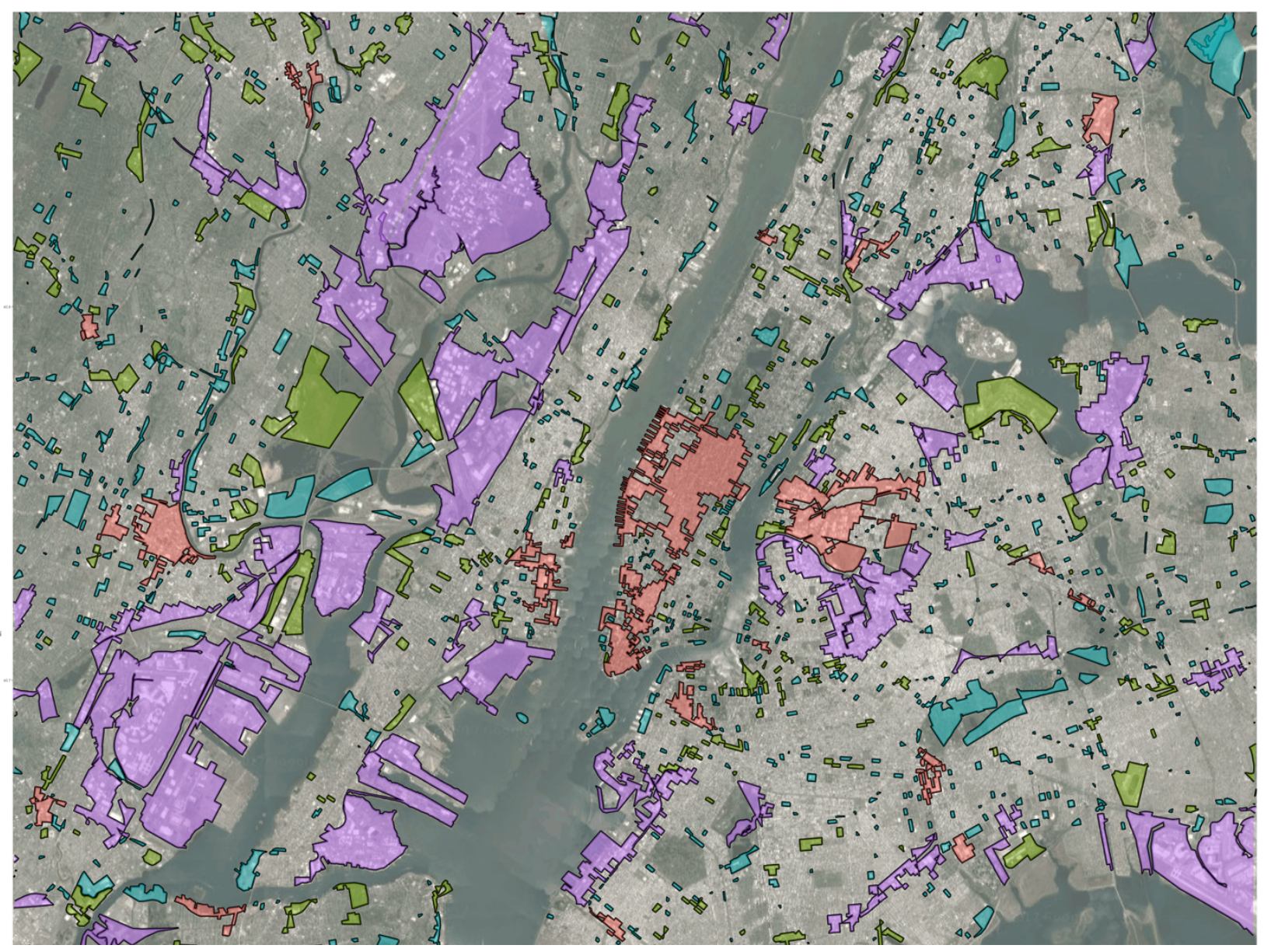

Figure 8: Business districts by category, New York MSA. Urban cores are in salmon, suburban strips in purple, independent centers in green, and dispersed employment blocks in turquoise. 


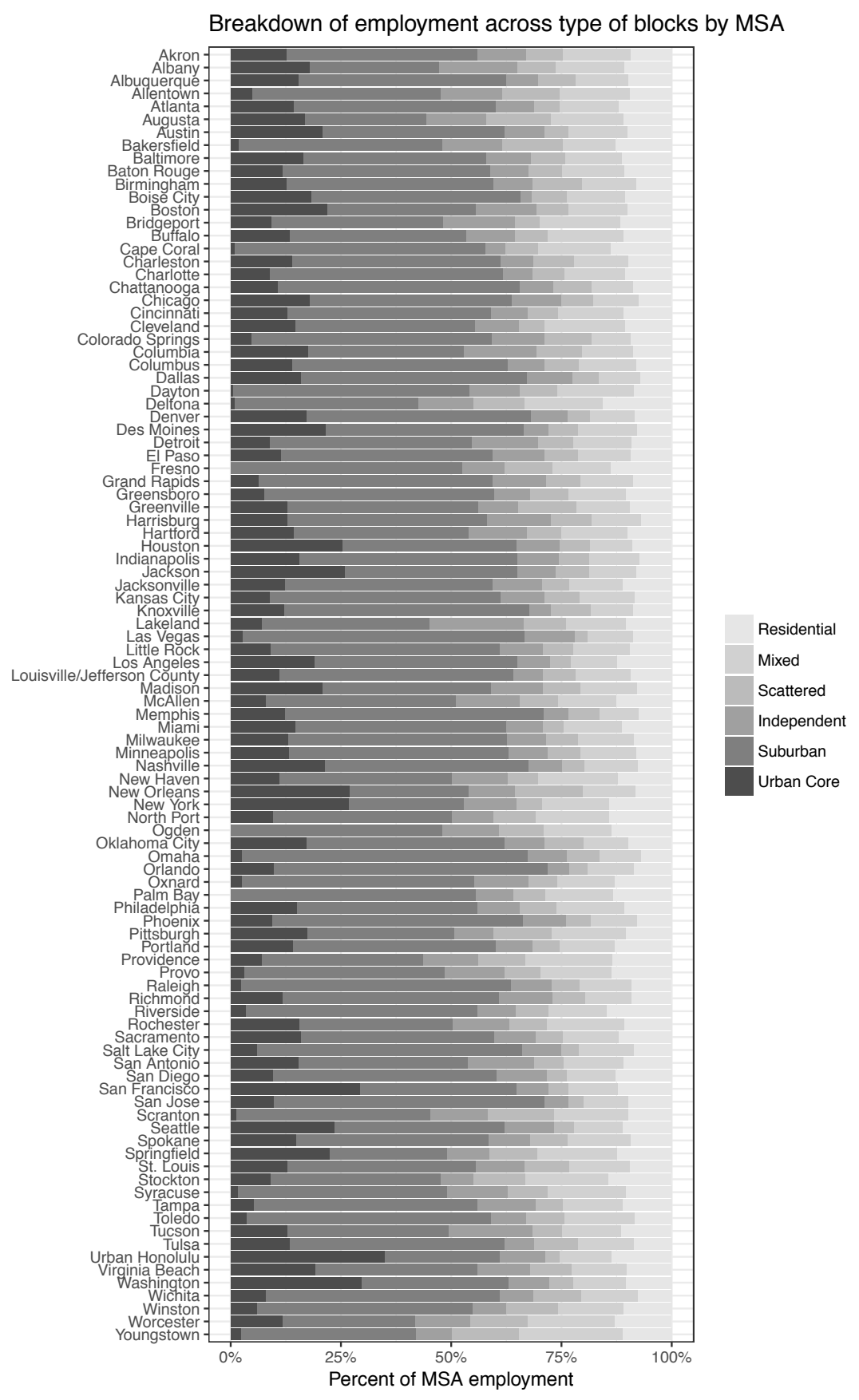

Figure 9: Metropolitan employment by district type, 100 largest MSAs 
Table 1: Overall breakdown of area, jobs, and population, 100 largest MSAs

\begin{tabular}{|l|r|r|r|r|r|r|r|r|}
\hline \multirow{2}{*}{ Category } & \multicolumn{2}{|c|}{ Land Area } & \multicolumn{2}{c|}{ Jobs } & \multicolumn{2}{c|}{ Population } & \multicolumn{1}{c|}{ Blocks } \\
\cline { 2 - 10 } & Square $\mathbf{~ k m}$ & \multicolumn{1}{c|}{$\%$} & \multicolumn{1}{c|}{ Count } & \multicolumn{1}{c|}{$\%$} & \multicolumn{1}{c|}{ Count } & \multicolumn{1}{c|}{ Count } & \multicolumn{1}{c|}{$\%$} \\
\hline Residential & 708,508 & $88.1 \%$ & $9,012,242$ & $10.4 \%$ & $188,587,285$ & $92.5 \%$ & $2,517,614$ & $85.1 \%$ \\
\hline Mixed & 44,022 & $5.5 \%$ & $11,040,647$ & $12.8 \%$ & $11,499,521$ & $5.6 \%$ & 134,027 & $4.5 \%$ \\
\hline Urban core & 881 & $0.1 \%$ & $13,882,637$ & $16.1 \%$ & 447,412 & $0.2 \%$ & 30,355 & $1.0 \%$ \\
\hline Suburban strip & 23,750 & $3.0 \%$ & $37,704,012$ & $43.7 \%$ & $1,938,328$ & $1.0 \%$ & 172,439 & $5.8 \%$ \\
\hline Independent & 4,094 & $0.5 \%$ & $8,696,091$ & $10.1 \%$ & 639,170 & $0.3 \%$ & 14,453 & $0.5 \%$ \\
\hline Dispersed & 23,161 & $2.9 \%$ & $5,945,263$ & $6.9 \%$ & 743,130 & $0.4 \%$ & 91,170 & $3.1 \%$ \\
\hline Total & $\mathbf{8 0 4 , 4 1 7}$ & $\mathbf{1 0 0 \%}$ & $\mathbf{8 6 , 2 8 0 , 8 9 2}$ & $\mathbf{1 0 0 \%}$ & $\mathbf{2 0 3 , 8 5 4 , 8 4 6}$ & $\mathbf{1 0 0 \%}$ & $\mathbf{2 , 9 6 0 , 0 5 8}$ & $\mathbf{1 0 0 \%}$ \\
\hline
\end{tabular}




\section{Supplementary Materials}

Appendix 1. Built land area as a proportion of total land area, largest 100 MSAs

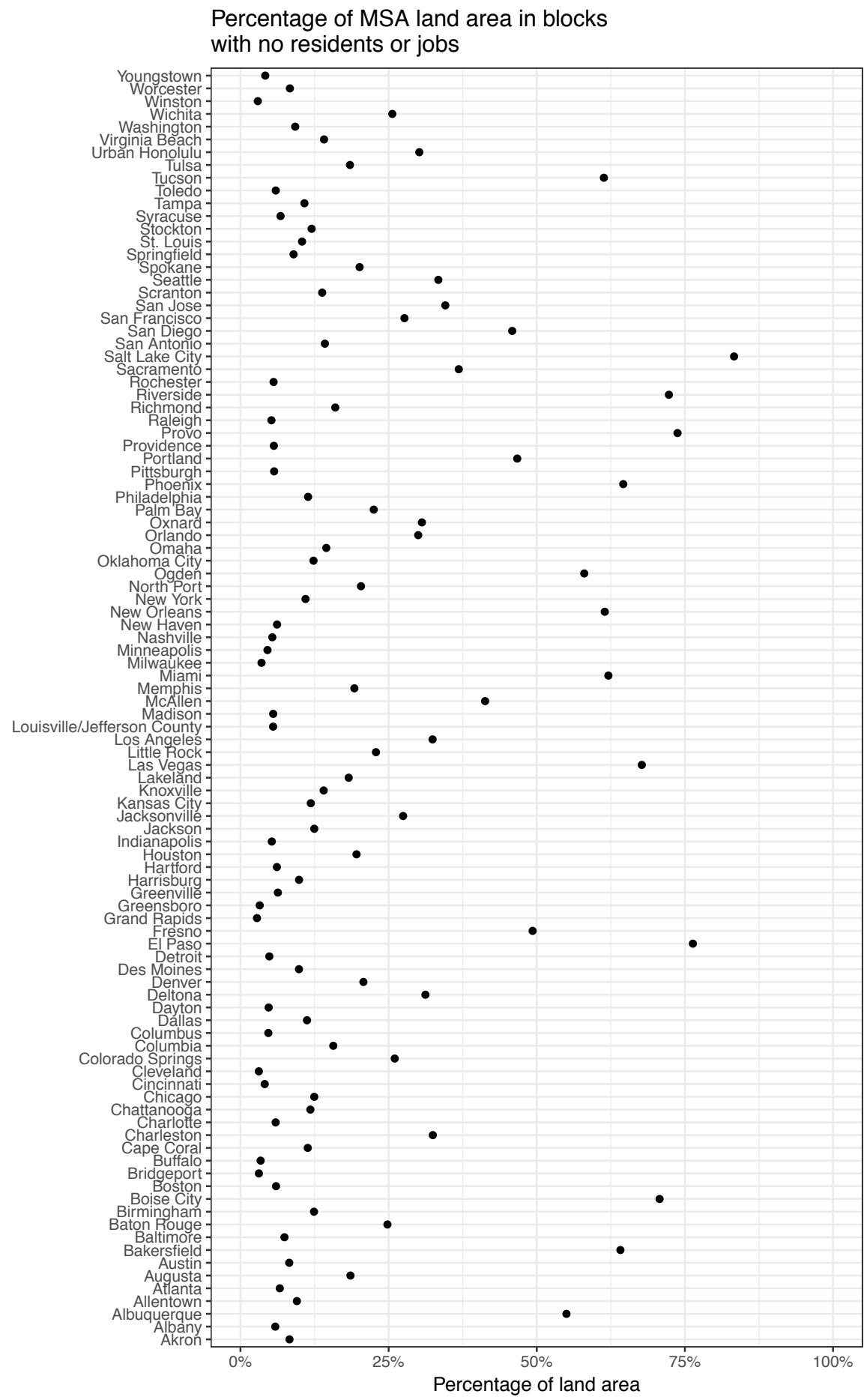


Appendix 2. Correlation between residential and employment densities

The consistency in allocation of jobs and land across cities is striking given the extreme variation in population and employment density among the largest 100 MSAs. As Figures 1 and 2 indicate, American cities vary enormously in the density at which they are constructed. And yet the patterns in Figure 5 suggest that while the absolute level of density may vary between San Francisco and Birmingham, the relative density of employment and population must be similar across metros. This consistent relationship between employment and population density is shown in Figure 6, which plots the median residential and employment density for each MSA. The range is impressive: the median resident of New York city lives at a density more than ten times that of the median resident of Birmingham or Knoxville, and works at a density more than 3.5 times as great. Median residential density varies by a factor of 14 across the 100 largest MSAs, while median employment density varies by a factor of 8 . But the median employment and population densities are highly correlated $(\mathrm{r}=0.72)$. There are few places with extremely dense downtowns and sparse suburbs: Washington, DC is the most prominent, with a median employment density of $9200 \mathrm{jobs} / \mathrm{km}^{2}$ and a median residential density of 2500 people $/ \mathrm{km}^{2}-$ still in the top quarter of metros. Stockton, CA is the clearest outlier in the opposite direction, with a relatively high median residential density of 3400 people $/ \mathrm{km}^{2}$ but a very low employment density of $1655 \mathrm{jobs} / \mathrm{km}^{2}$. 


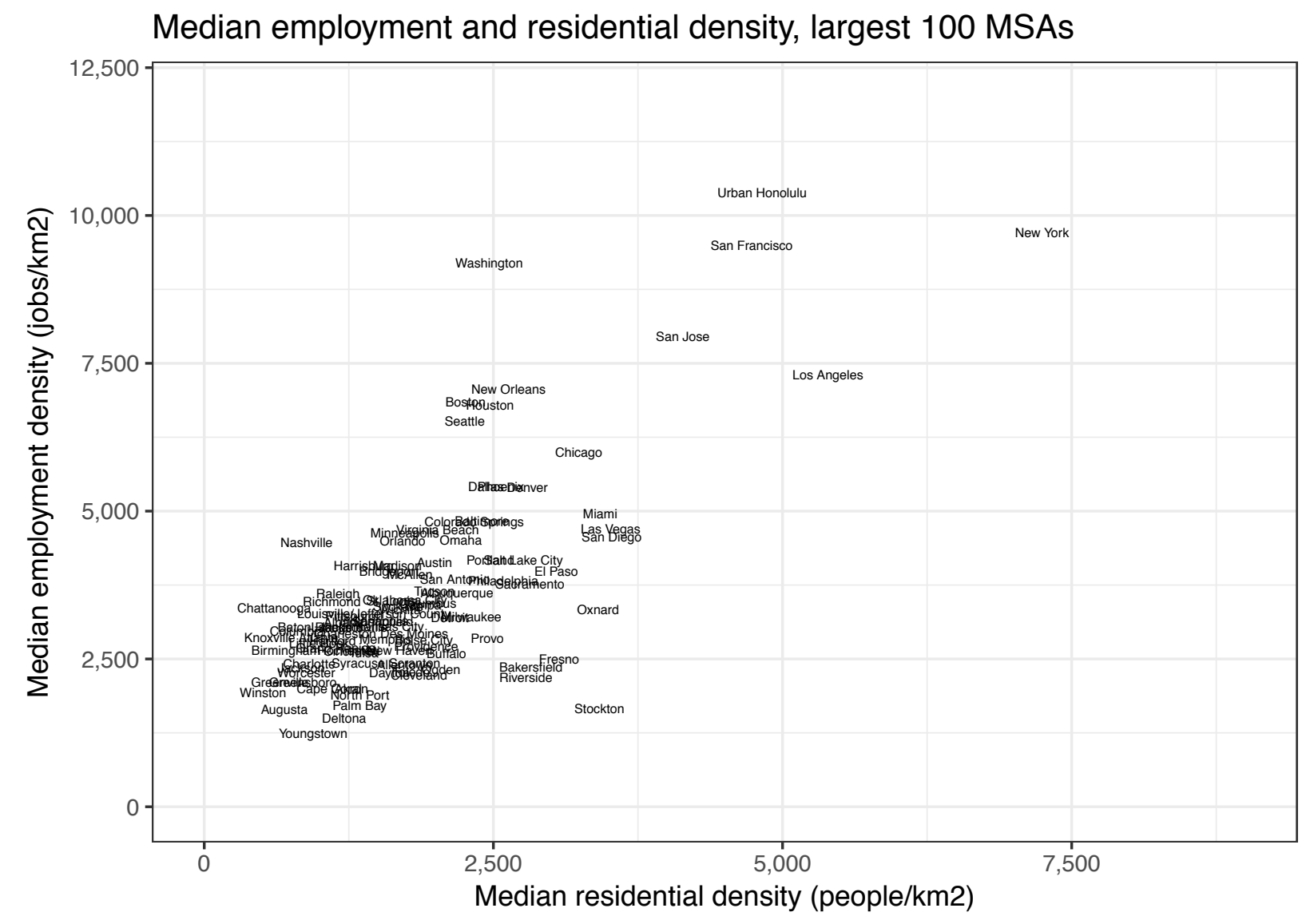

Figure A2.1 Median residential and population density, 100 largest MSAs 
Appendix 3. Observed clustering compared to expected clustering under randomness, largest 100 MSAs

Observed clustering compared to randomness

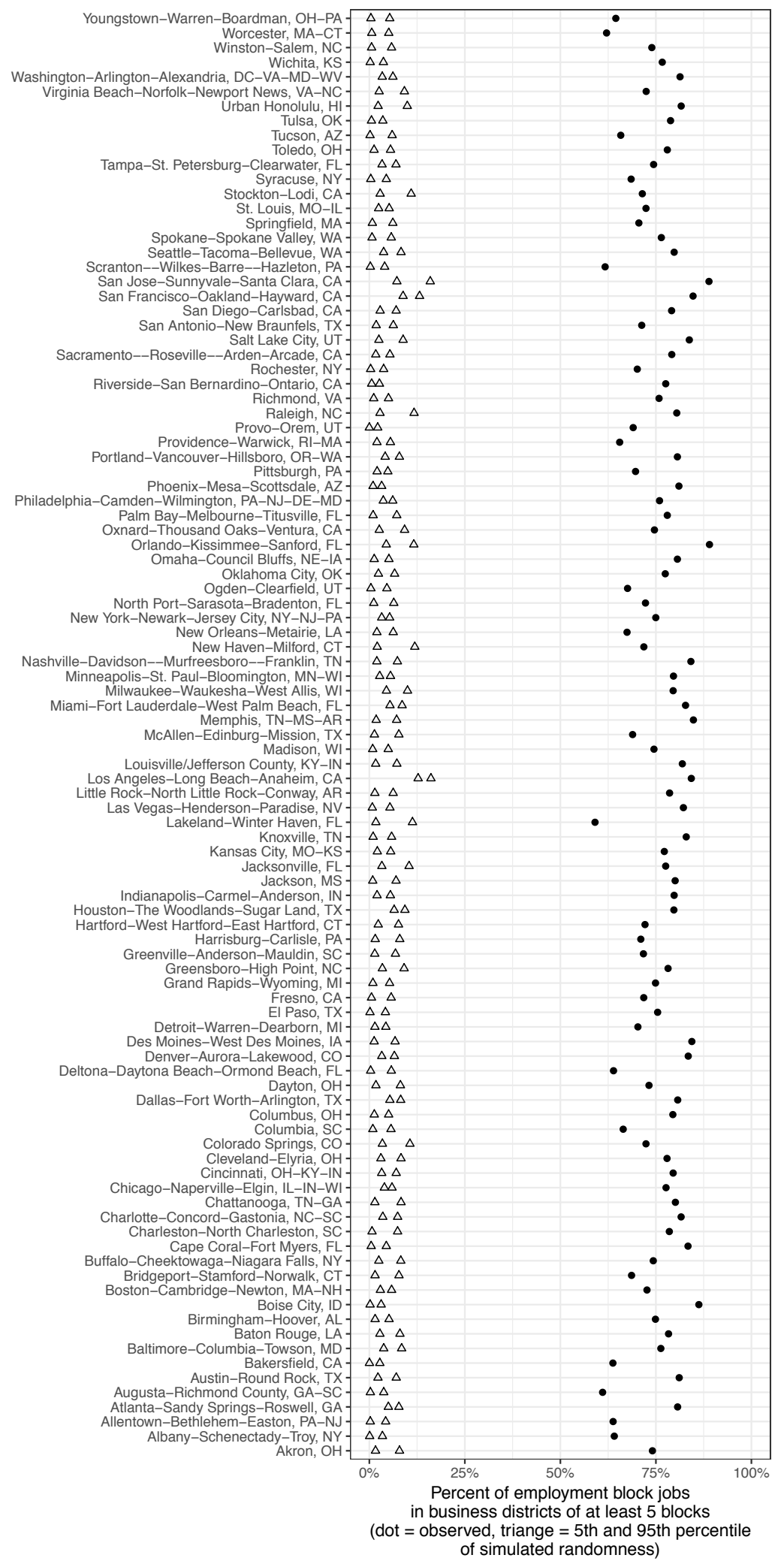




\section{Appendix 4. Summary statistics of business districts by MSA}

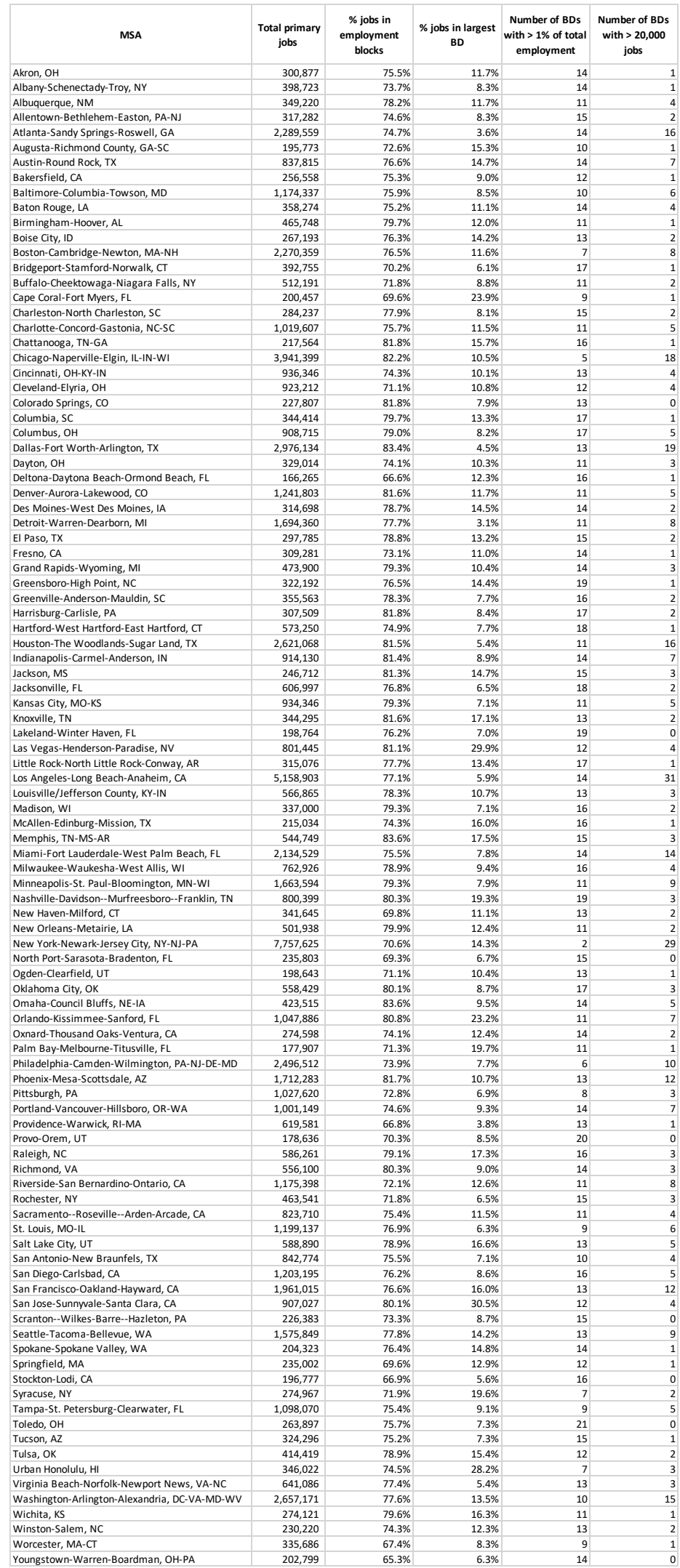


Appendix 5. Scaling patterns of business districts.

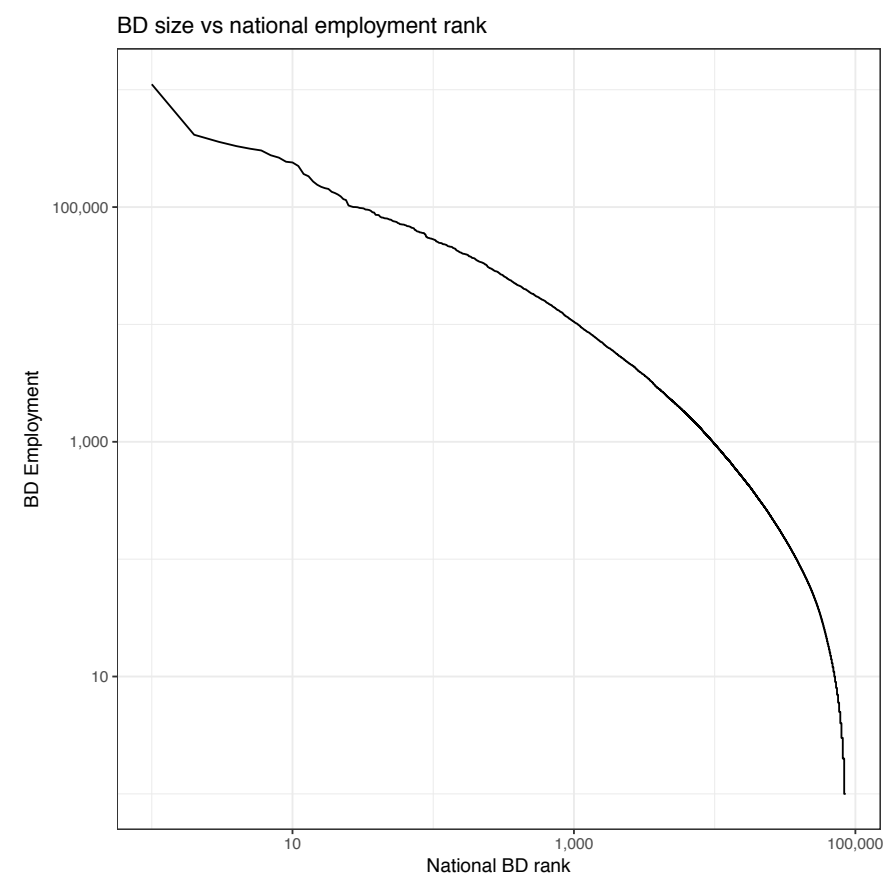

Figure A4.1: National scaling patterns of business district size and rank

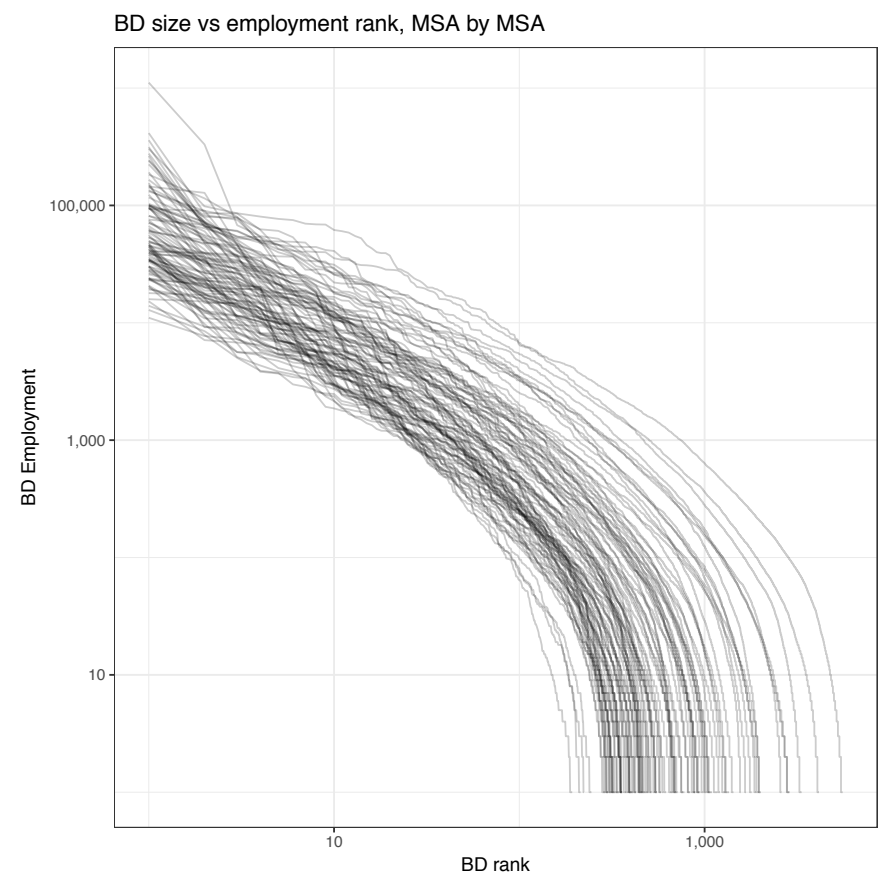

Figure A4.2: MSA by MSA scaling patterns of business district size and rank 
Appendix 6. Summary statistics of the 20 largest business districts in the US

\begin{tabular}{|c|c|c|c|c|c|c|c|c|}
\hline $\begin{array}{c}\text { National } \\
\text { Rank }\end{array}$ & Business district name & MSA name & $\begin{array}{c}\text { Rank within } \\
\text { MSA }\end{array}$ & $\begin{array}{c}\text { Total } \\
\text { employment }\end{array}$ & $\begin{array}{l}\text { Resdential } \\
\text { population }\end{array}$ & $\begin{array}{l}\text { Land Area } \\
\text { (sq. km) }\end{array}$ & $\begin{array}{l}\text { Count of } \\
\text { blocks }\end{array}$ & Category \\
\hline 1 & Midtown Manhattan & New York & 1 & $1,112,861$ & 65,143 & 7.0 & 431 & Urban core \\
\hline 2 & Chicago Loop & Chicago & 1 & 413,306 & 8,685 & 4.9 & 425 & Urban core \\
\hline 3 & Downtown Washington DC & Washington & 1 & 359,459 & 8,210 & 9.9 & 388 & Urban core \\
\hline 4 & Downtown Manhattan & New York & 2 & 330,343 & 19,220 & 2.4 & 250 & Urban core \\
\hline 5 & Downtown San Francsico & San Francisc & 1 & 314,206 & 8,964 & 4.9 & 372 & Urban core \\
\hline 6 & Downtown LA & Los Angeles & 1 & 303,711 & 6,693 & 21.8 & 676 & Urban core \\
\hline 7 & Northern San Jose & San Jose & 1 & 276,294 & 4,273 & 73.0 & 602 & Suburban strip \\
\hline 8 & Downtown Boston/Back Bay & Boston & 1 & 263,831 & 10,492 & 2.8 & 248 & Urban core \\
\hline 9 & Southern Orlando & Orlando & 1 & 243,343 & 3,886 & 88.8 & 360 & Suburban strip \\
\hline 10 & Las Vegas Strip & Las Vegas & 1 & 239,982 & 2,094 & 29.3 & 204 & Suburban strip \\
\hline 11 & Downtown Seattle & Seattle & 1 & 223,859 & 6,633 & 16.6 & 554 & Urban core \\
\hline 12 & Center City Philadelphia & Philadelphia & 1 & 191,284 & 5,315 & 2.2 & 216 & Urban core \\
\hline 13 & Downtown Phoenix/Airport & Phoenix & 1 & 183,040 & 2,643 & 70.1 & 461 & Suburban strip \\
\hline 14 & Western Miami industrial zone & Miami & 1 & 167,154 & 1,656 & 88.1 & 503 & Suburban strip \\
\hline 15 & Downtown Nashville & Nashville & 1 & 154,835 & 4,668 & 13.3 & 506 & Urban core \\
\hline 16 & Ontario industrial area & Riverside & 1 & 148,672 & 1,919 & 92.9 & 365 & Suburban strip \\
\hline 17 & Colorado Tech Center & Denver & 1 & 144,961 & 2,388 & 35.4 & 232 & Suburban strip \\
\hline 18 & Downtown Houston & Houston & 1 & 142,797 & 870 & 3.1 & 271 & Urban core \\
\hline 19 & North Dallas & Dallas & 1 & 134,872 & 1,437 & 19.3 & 287 & Suburban strip \\
\hline 20 & Downtown Minneapolis & Minneapolis & 1 & 131,837 & 3,408 & 5.4 & 194 & Urban core \\
\hline
\end{tabular}




\section{Appendix 7. Comparison of city centers as identified by the CBD algorithm and by Google Maps}

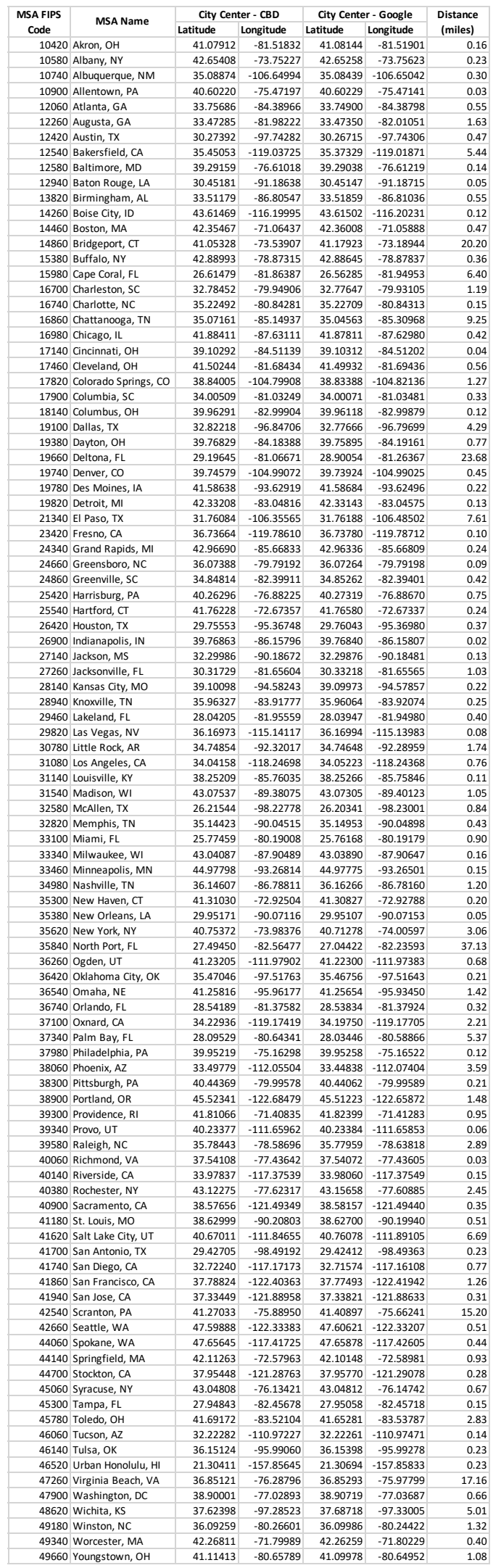

